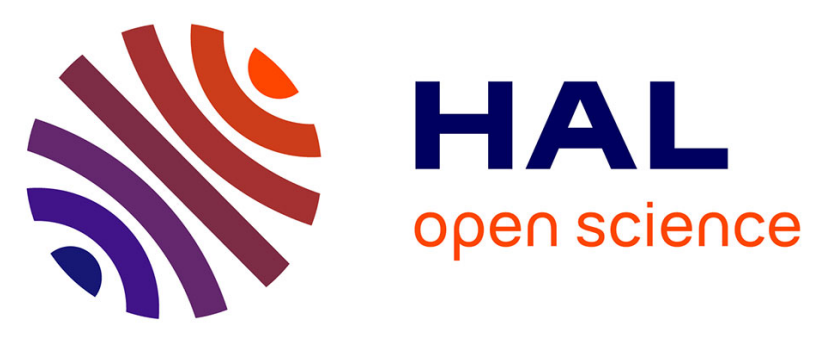

\title{
Soluble CD14 acts as a DAMP in human macrophages: origin and involvement in inflammatory cytokine/chemokine production
}

Manuella Leveque, Karin Simonin-Le Jeune, Stéphane Jouneau, Solenn Moulis, Benoit Desrues, Chantal Belleguic, Graziella Brinchault, Sophie Le Trionnaire, Jean-Pierre Gangneux, Marie-Thérèse Dimanche-Boitrel, et al.

\section{To cite this version:}

Manuella Leveque, Karin Simonin-Le Jeune, Stéphane Jouneau, Solenn Moulis, Benoit Desrues, et al.. Soluble CD14 acts as a DAMP in human macrophages: origin and involvement in inflammatory cytokine/chemokine production. FASEB Journal, 2017, 31 (5), pp.1891-1902. 10.1096/fj.201600772R . hal-01526434

\section{HAL Id: hal-01526434}

\section{https://hal-univ-rennes1.archives-ouvertes.fr/hal-01526434}

Submitted on 12 Jul 2017

HAL is a multi-disciplinary open access archive for the deposit and dissemination of scientific research documents, whether they are published or not. The documents may come from teaching and research institutions in France or abroad, or from public or private research centers.
L'archive ouverte pluridisciplinaire HAL, est destinée au dépôt et à la diffusion de documents scientifiques de niveau recherche, publiés ou non, émanant des établissements d'enseignement et de recherche français ou étrangers, des laboratoires publics ou privés. 
4 Manuella Lévêque ${ }^{*}+$, Karin Simonin-Le Jeune ${ }^{*} \ddagger$, Stéphane Jouneau ${ }^{\dagger, \ddagger}$, , Solenn Moulis ${ }^{*}, \ddagger$ 5 Benoit Desrues ${ }^{\S, *, \phi}$, Chantal Belleguic ${ }^{\S}$, Graziella Brinchault ${ }^{\S}$, Sophie Le Trionnaire ${ }^{*}$, Jean-

7 *Research Institute for Environnemental and Occupationnal Health (IRSET) INSERM U1085, 8 team 'Stress Membrane and Signaling,' F-35043 Rennes, France.

$9 \quad$ Tesearch Institute for Environnemental and Occupationnal Health (IRSET) INSERM U1085,

\section{Soluble CD14 acts as a DAMP in human macrophages: origin and involvement in inflammatory cytokine/chemokine production} team 'Chemical contaminant immunity and inflammation,' F-35043 Rennes, France.

*University of Rennes 1, UMS Biosit, F-35000 Rennes, France.

${ }^{\S}$ Centre Hospitalier Universitaire de Rennes, Centre de Ressource et de Compétences de la Mucoviscidose, F-35064 Rennes, France

${ }^{\phi}$ URL440-COSS, Centre Eugène Marquis, F-35064 Rennes, France

\section{${ }^{1}$ Corresponding author:}

Dr. Corinne Martin-Chouly

2, avenue du Pr Léon Bernard

35043 RENNES Cedex FRANCE

E-mail: corinne.chouly@univ-rennes1.fr

Tel: (+33) 223234904

Fax: (+33) 223235055

Short title: sCD14 in human macrophages

25

26

7




\section{ABBREVIATIONS}

30

31 Abbreviations used in this article: sCD14, soluble form of CD14; CF, cystic fibrosis; DAMPs, 32 danger-associated molecular patterns; ER, Endoplasmic Reticulum; FEV1, Force Expiratory 33 Volume in one second; NLRs, NOD-like receptors; PAMPs, pathogen-associated molecular 34 patterns; PI-PLC, phosphatidylinositol-phospholipase C.

35 
38 The innate immune system is able to detect bacterial lipopolysaccaride (LPS) through the pattern 39 recognition receptor CD14, which delivers LPS to various TLR signaling complexes that 40 subsequently induce intracellular pro-inflammatory signaling cascades. In a previous study, we 41 showed the overproduction of the soluble form of CD14 (sCD14) by macrophages from patients 42 with cystic fibrosis (CF). CF is an autosomal recessive disorder that is caused by mutations in the 43 gene that encodes the CFTR protein and characterized by persistent inflammation. Macrophages 44 play a significant role in the initial stages of this disease due to their inability to act as suppressor 45 cells leading to chronic inflammation in CF. In this work, we investigated the origin of sCD14 by 46 human macrophages and studied the effect of $\mathrm{sCD} 14$ on the production of inflammatory 47 cytokine/chemokine. Our data indicate that SCD14 stimulate pro-inflammatory 48 cytokine/chemokine production in a manner that is independent of LPS but dependent on the 49 TLR-4/CD14 membrane complex, NF- $\kappa \mathrm{B}$ and the inflammasome. Therefore sCD14, 50 overproduced by CF macrophage, originates primarily from the endocytosis/exocytosis process 51 and should be considered to be a DAMP. In fact, this elucidation of the origin and inflammation52 induced mechanisms associated with sCD14 contributes to our understanding of maintained 53 tissue inflammation.

55 Key words: inflammation, cystic fibrosis, NF- $\kappa B$, inflammasome 


\section{INTRODUCTION}

62 CD14 was first characterized as a membrane-associated GPI-anchored protein and a cell surface 63 differentiation marker that is present on the surface of monocytes, macrophages, dendritic cells 64 and neutrophils (1-5). CD14 acts as a receptor for bacterial LPS in cooperation with TLR-4 and $652(5,6)$ and can bind various bacterial ligands and receptors on phagocytes, thereby mediating the phagocytosis of bacteria and the clearance of apoptotic cells (4, 7-9). CD14 also exists as two soluble forms: a form with a low molecular mass of 48-50 kDa and a form with a high molecular mass of 53-56 $\mathrm{kDa}$. The mechanisms of CD14 production have been reported to be linked to neosynthesis, proteolytic or GPI-tail cleavage by phospholipases or endocytosis/exocytosis (2, 3, 10-18). In cells that express membrane CD14, including mononuclear cells, high concentrations of sCD14 are able to inhibit LPS-mediated functional responses $(19,20)$. In cells that lack membrane CD14, including most epithelial and endothelial cells, sCD14 enables these cells to respond to LPS $(8,21)$. At the local site of infection, pro-inflammatory signals that result from sCD14 can be protective, leading to local clearance of invading bacteria. However, widespread infection and activation of this pro-inflammatory signaling pathway can cause fatality through sepsis $(22,23)$. Furthermore, significant levels of sCD14 were detected in both serum and bronchoalveolar lavage fluid from patients with acute respiratory distress syndrome (24). In addition, it was demonstrated in a murine model that Streptococcus pneumoniae uses sCD14 in the bronchoalveolar space to cause invasive respiratory tract infections (25). Overall, sCD14 appears to act as a key component during pulmonary inflammation/infection.

Chronic bacterial airway infection and subsequent intense neutrophilic inflammation with the release of intracellular proteases are considered to be the main contributors to bronchiectasis and 84 end-stage lung disease CF patients. Recent research highlighted the worsening role of inflammation and immune responses in CF airway disease (26). Macrophages are antigenpresenting phagocytes that secrete pro-inflammatory mediators and antimicrobial factors in

87 response to challenge by extracellular pathogens. Recently, several studies showed that specific features of macrophage activation in CF patients play an important role during the CF disease process (27-29). In our previous work, we observed an increase in SCD14 secretion by peripheral monocyte-derived macrophages from stable adult CF patients (29). However, the origin and 
91 involvement of sCD14 has not been studied. In this work, we examined the mechanisms involved 92 in the release of $\mathrm{SCD} 14$ by peripheral monocyte-derived macrophages from adult with $\mathrm{CF}$ and the 93 inflammatory signaling pathways that are induced by sCD14 in non CF cells.

94 


\section{CF patients}

The experiments were conducted according to the Good Clinical Practice guidelines (Kong, 1997) and approved by the Ethics Committee for human subjects of Rennes University Hospital (France, Ethics No. 11/38-827). All patients included in this study gave written informed consent. Sixty stable adult patients with $\mathrm{CF}$ were recruited at the 'Centre de Ressources et de Compétences pour la Mucoviscidose' of Rennes University Hospital (France). The CF patients considered for inclusion were Caucasian and included 27 males and 33 females, who were aged between 18 and 52 years (mean age: $30 \pm 9$ ). The CF diagnosis was based on typical clinical manifestations of the disease and confirmed by positive sweat tests and by CFTR gene mutation detection. Stable patients were defined by the absence of changes in symptoms in the 3 months prior to the study. All patients with $\mathrm{CF}$ received medication at the time of blood collection, including azithromycin (27\%), aerosol DNAse (48\%), inhaled corticosteroids (72\%) and azole therapy (47\%). Oral corticosteroid therapy at the time of blood collection was an exclusion criterion, as this therapy may influence inflammatory phenotypes. Patients with the G551D mutation were not treated with ivacafor at the time of their participation in the study (except for patient 19, supplemental Table 1). The clinical features of the patients are reported in supplemental Table 1. According to the FEV1 values (\% predicted), the majority of our patients (41/60) had mild to moderate lung disease (FEV1 values $\geq 55 \%$ ). In their sputum samples, 32 patients had microbiological evidence of Pseudomonas aeruginosa, and Staphylococcus aureus and Aspergillus fumigatus were detected in 45 and 29 patients, respectively. The CF genotypes

117 were representative of the French CF population, with $57 \%$ of participants having F508del/F508del mutations, 36\% of patients having F508del/other mutations and 7\% of patients having no F508del mutations (30). Blood monocyte counts were within the normal range, with a median number of $0.679 \times 10^{9} / \mathrm{L}$ (range $0.23-1.12 \times 10^{9} / \mathrm{L}$ ).

\section{Cell cultures and treatments}

123 Leukocytes were isolated by Ficoll gradient centrifugation, as described previously (31).

124 Peripheral blood mononuclear cells from healthy non-CF subjects (written consent for the use of 
125

126

127

128

129

130

131

132

133

134

135

136

137

138

139

140

141

142

143

144

145

146

147

148

149

150

151

152

153

154

155

blood samples for the research protocol was obtained, according to the regulation for blood transfusion of the French blood organization EFS, Rennes) were seeded according to the specific blood count of each subject. Monocytes, which were selected via a 1-hour adhesion step, were differentiated for 6 days using GM-CSF (400 UI/ml, Genzyme, Lyon, France) in RPMI 1640 medium supplemented with $2 \mathrm{mM}$ glutamine, antibiotics and 10\% FBS (Lonza, Levallois Perret, France). Before treatment, the macrophages were placed in medium without serum for 24 hours. To study proteolytic origin of sCD14, non-CF macrophages were treated by e64d ( $1 \mu \mathrm{M}$, SigmaAldrich, Saint-Quentin Fallavier, France), pepstatin A (1 $\mu \mathrm{M}$, Sigma-Aldrich, Saint-Quentin Fallavier, France), EDTA (0.1 mM, Sigma-Aldrich, Saint-Quentin Fallavier, France) or aprotinin (0.3 $\mu \mathrm{g} / \mathrm{ml}$, Sigma-Aldrich, Saint-Quentin Fallavier, France) for 24 hours. To study GPI-tail cleavage by phospholipase, PI-PLC (1 U/ml, Life Technologies, ThermoFisher Scientific, Saint Aubin, France) was added to non-CF macrophages for 2 hours in the absence or presence of the PI-PLC inhibitor U-73122 (12.5 $\mu \mathrm{M}$, 1-hour pretreatment, Bertin Pharma, Montigny le Bretonneux, France). In parallel, macrophages from CF patients were treated with U-73122 for 24 hours. To study membrane trafficking pathways, the cells were supplemented with watersoluble cholesterol (15 to $30 \mu \mathrm{g} / \mathrm{ml}$, 1-hour pretreatment, followed by 24 hours, Sigma-Aldrich, Saint-Quentin Fallavier, France) or with brefeldin A (100 ng/ml, 1-hour pretreatment, followed by $2 \mathrm{~h}$, Cell Signaling Technology, Ozyme, Saint Quentin en Yvelines, France). To study inflammatory signaling pathways, human recombinant sCD14 protein $(500 \mathrm{ng} / \mathrm{ml},<0.1 \mathrm{EU} / \mu \mathrm{g}$ endotoxin, Sigma-Aldrich, Saint-Quentin Fallavier, France) was added to non-CF macrophages for 24 hours in the absence or presence of Bay 11-7082 (1 and $10 \mu \mathrm{M}, 1$-hour pretreatment, Calbiochem, Merck Millipore, Molsheim, France) or the caspase inhibitor Z-WEHD-FMK (1 to $30 \mu \mathrm{M}, 30$-min pretreatment, Calbiochem, Merck Millipore, Molsheim, France). To study TLR involvement in the inflammatory effect of sCD14, sCD14 was added to non-CF macrophages in the presence of the TLR-4 antagonist LPS-RS (LPS from the photosynthetic bacterium Rhodobacter sphaeroides, $2 \mu \mathrm{g} / \mathrm{ml}$, InvivoGen, Toulouse, France), a CD14-neutralizing antibody (anti-hCD14 IgA, $10 \mu \mathrm{g} / \mathrm{ml}$, 1-hour pretreatment, InvivoGen, Toulouse, France), a TLR4neutralizing antibody (anti-hTLR4 IgA, $10 \mu \mathrm{g} / \mathrm{ml}$, 1-hour pretreatment, Invitrogen, ThermoFisher Scientific, Saint Aubin, France) or control IgG2a (10 $\mu \mathrm{g} / \mathrm{ml}$, 1-hour pretreatment, InvivoGen, Toulouse, France). At the doses used, the treatments did not affect the viability of the macrophages (data not shown). Viability was measured using the CellTiter 96® AQueous One 
Solution Cell Proliferation Assay (Promega, charbonnières les bains, France) according to the

157 instructions provided by the manufacturer.

\section{Gene expression}

RNA expression was analyzed using RT-qPCR assays. Briefly, total RNA was isolated from CF macrophages using NucleoSpin ${ }^{\circledR}$ RNA XS (Macherey Nagel, Hoerdt, France) and from non-CF macrophages using the PureLink RNA Mini Kit (Ambion ${ }^{\circledR}$, ThermoFisher Scientific, Saint Aubin, France). The total RNA $(1 \mu \mathrm{g})$ was reverse transcribed into cDNA using the High Capacity cDNA Reverse Transcription Kit (Applied Biosystems ThermoFisher Scientific, Saint Aubin, France). Real-time PCR was performed using the Power SYBR Green PCR Master kit (Applied Biosystems ThermoFisher Scientific, Saint Aubin, France) according to the manufacturer's instructions and an ABI Prism 7300 detector (Applied Biosystem ThermoFisher Scientific, Saint Aubin, France). The gene-specific primers for 18S, CD14, IL-1 $\beta$, IL-8 were Quantitect ${ }^{\circledR}$ Primer Assay primers obtained from Qiagen (Hilden, Germany). The gene-specific primers for 18S, TNF, MMP-9, MMP-12, Cathepsin B, Cathepsin D, Cathepsin F, Cathepsin K,

172 Eurogentec (Liège, Belgium). A list of the primer sequences used for the RT-qPCR analysis is reported in supplemental Table 2. The amplification curves of the PCR products were analyzed with the ABI Prism SDS software using the comparative cycle threshold (CT) method. Relative gene expression was calculated by comparing the number of thermal cycles that were necessary to generate threshold amounts of product (CT). The CT was calculated for the each gene and for the housekeeping gene $18 \mathrm{~S}$. For each cDNA sample, the $18 \mathrm{~S} \mathrm{CT}$ was subtracted from the CT for each gene to yield the $\Delta \mathrm{CT}$, thus normalizing the initial amount of RNA used. The amount of mRNA was calculated as $2^{-\Delta \Delta C T}$, where the $\Delta \Delta \mathrm{CT}$ is the difference between the $\Delta \mathrm{CT}$ of the two cDNA samples to be compared. The data from CF samples are expressed relative to the mRNA level found in non-CF samples. The data from the treatment samples are expressed relative to the mRNA level found in the controls.

\section{Cytokine/chemokine, sCD14 and NFKB p65 level quantification}


IL-1 $\beta$, IL-8, TNF- $\alpha$ and SCD14 levels were measured in the supernatants of the cell cultures and in plasma from CF patients using a Duoset ${ }^{\circledR}$ ELISA kit (R\&D system, Abingdon, United Kingdom), according to the instructions provided by the manufacturer. The NFKB p65 level was measured in the nuclear fraction of cell cultures using TransAM ${ }^{\circledR}$ NFkB p65 (Active Motif, La Hulpe, Belgium), according to the instructions provided by the manufacturer.

\section{Neosynthesis measurement}

Soluble CD14 neosynthesis was measured using Click-IT ${ }^{\circledR}$ technology (Thermo-fischer scientific). Macrophages were placed in RPMI 1640 medium without methionine (Gibco, ThermoFisher Scientific, Saint Aubin, France). After $30 \mathrm{~min}$ incubation $\left(37^{\circ} \mathrm{C}, 5 \% \mathrm{CO}_{2}\right)$, macrophages were pulse-chase labeled in the presence of Click-IT® L- Azidohomoalanin (50 $\mu$ M; Molecular Probes, ThermoFisher Scientific, Saint Aubin, France) in RPMI 1640 medium without methionine for 3 hours. Afterwards, medium was changed by RPMI 1640 with methionine and macrophages were incubated for 21 hours $\left(37^{\circ} \mathrm{C}, 5 \% \mathrm{CO}_{2}\right)$. Then supernatants were recovered and analyzed for sCD14 level quantification using Duoset ${ }^{\circledR}$ ELISA kit (R\&D system, Abingdon, United Kingdom). . To measure neosynthesis, biotin-coupled detection antibody was substituted by Click-IT ${ }^{\circledR}$ Biotin DIBO Alkyne (Molecular Probes, ThermoFisher Scientific, Saint Aubin, France), for copper-free click chemistry.

\section{Cholesterol level quantification}

Total lipids were extracted with $200 \mu 1 \mathrm{CHCl}_{3} / \mathrm{MeOH} / \mathrm{NP}-40$ (7:11:0.1; v/v). The sample was centrifuged for $10 \mathrm{~min}$ at 14,000 rpm. The chloroformic layer was evaporated to dryness under a nitrogen stream. Then, the free cholesterol levels was determined using Cholesterol/Cholesteryl Ester Quantitation Kit (Merck Millipore, Molsheim, France), according to the instructions provided by the manufacturer. Cholesterol is oxidized by cholesterol oxidase to yield $\mathrm{H}_{2} \mathrm{O}_{2}$. The resulting $\mathrm{H}_{2} \mathrm{O}_{2}$ interacts with a sensitive cholesterol probe to produce resorufin, which can be detected by spectrophotometrically $570 \mathrm{~nm}$. Total protein concentrations were determined using a BCA protein assay kit (Thermoscientific, Saint Aubin, France) to express cholesterol based on the protein concentration for each sample. 


\section{Zymography assay}

216 The gelatinolytic activity of secreted MMP-9 was analyzed using gelatin zymography, as 217 described previously (32). The samples were subjected to electrophoresis via 10\% SDS-PAGE 218 containing $1 \mathrm{mg} / \mathrm{ml}$ of gelatin (Sigma Aldrich, Saint-Quentin Fallavier, France) under non219 reducing conditions. After electrophoresis, the gels were washed twice with $2.5 \%$ Triton X-100, 220 rinsed with water, and incubated at $37^{\circ} \mathrm{C}$ overnight in reaction buffer $\left(50 \mathrm{mM}\right.$ Tris, $5 \mathrm{mM} \mathrm{CaCl}_{2}$, 221 and $2.1 \mathrm{mM} \mathrm{ZnCl}_{2}, \mathrm{pH}$ 8.0). The gels were stained with Coomassie brilliant blue (Sigma Aldrich, 222 Saint-Quentin Fallavier, France) and de-stained in a solution of 25\% ethanol and 10\% acetic acid.

223 Gelatinase activity appeared as clear bands against a blue background. The molecular weights of 224 the gelatinolytic bands were estimated using a prestained protein ladder (10 - $250 \mathrm{kDa}$, 225 Euromedex, Souffelweyersheim, France). Images of the zymograms were acquired using the Gel 226 Doc 1000 Gel Documentation System (Bio-Rad laboratories, Marnes-La -Coquette, France), and 227 both the surface and intensity of the lysis bands were quantified by densitometry using the 228 MultiGauge software (Fujifilm, Tokyo, Japan).

230 Gene silencing by siRNA

231 ON-TARGETplus siRNAs against NLRC4 or NLRP3 were synthesized and annealed by 232 Dharmacon RNAi Technologies (ThermoFisher Scientific, Saint Aubin, France). siRNA 233 duplexes were transfected using the Lipofectamine RNAiMAX Reagent (Life Technologies, 234 ThermoFisher Scientific, Saint Aubin, France). The transfection reagent and siRNAs were mixed, 235 and complex formation was allowed to proceed for $5 \mathrm{~min}$ at room temperature before the 236 complex was added to the macrophages. After 72 hours, the cells were treated or not treated with $237 \mathrm{sCD} 14$ (500 ng/ml, 24 hours) before being harvested for analysis.

\section{Immunoblotting}

240 Membrane-bound proteins were extracted from the macrophages by lysing the cells with RIPA 241 lysis buffer (50 mM Tris- $\mathrm{HCl}$ pH 7.5, $150 \mathrm{mM} \mathrm{NaCl}, 1 \mathrm{mM}$ EDTA, 0.1\% SDS, 1\% Triton-X100, $24212 \mathrm{mM}$ deoxycholate, $2 \mathrm{mM} \mathrm{NaF}, 1 \mathrm{mM} \mathrm{Na}_{3} \mathrm{VO}_{4}, 2 \mathrm{mM}$ PMSF, cOmplete ${ }^{\mathrm{TM}}$ EDTA-free 243 Protease Inhibitor Cocktail (Roche, Bâle, Switzerland) and PhosSTOP Phosphatase Inhibitor 244 Cocktail (Roche, Bâle, Switzerland). The macrophages were incubated at $4^{\circ} \mathrm{C}$ for 30 minutes in 245 lysis buffer with vortexing for 30 seconds every 10 minutes. The supernatant containing proteins 
246 was obtained by subsequent centrifugation at $10,000 \mathrm{~g}$ for 10 minutes at $4^{\circ} \mathrm{C}$, and the protein 247 concentration was determined using a BCA protein assay kit (ThermoFisher Scientific, Saint 248 Aubin, France). Proteins were separated via SDS-PAGE and transferred to a nitrocellulose 249 membrane. Then, the membrane was subjected to western blotting using a rabbit anti-IкB $\alpha$, rabbit 250 anti-P-I $\kappa \mathrm{B} \alpha$, rabbit polyclonal anti-Caspase 1, mouse anti-IL-1 $\beta$, rabbit anti-NLRP3, rabbit anti251 NLRC4 (Cell Signaling Technology, Ozyme, Saint Quentin en Yvelines, France), rabbit anti252 CD14 (Epitomics, Burlingame, CA, US) or mouse anti-HSC70 (Santa Cruz, Heidelberg, 253 Germany) antibodies. Horseradish peroxidase-conjugated goat anti-rabbit (Cell Signaling 254 Technology, Ozyme, Saint Quentin en Yvelines, France) or goat anti-mouse (Dako, Les Ulis, 255 France) antibodies were used as secondary antibodies, and proteins were detected using enhanced 256 chemiluminescence. The images were scanned with the Fujifilm LAS-3000 imager (Fujifilm, 257 Tokyo, Japan) and analyzed with the MultiGauge software (Fujifilm, Tokyo, Japan) for 258 densitometry. The intensity of the bands was normalized based on HSC-70.

\section{Statistical analysis}

261 The number of subjects and experiments used in each group is stated in the respective figures. 262 Statistical significance was evaluated by using the GraphPad Prism software v.6.0 (GraphPad 263 Software Inc., San Diego, CA, US). A non-parametric Mann-Whitney test was used to assess the 264 statistical significance of differences between non-CF and $\mathrm{CF}$ groups. A parametric ratio 265 Student's t-test was used to assess statistical significance between treatments. For each analysis, a 266 p-value $<0.05$ was considered to be significant. 
RESULTS

\section{Origin of sCD14 in human CF macrophages}

We previously observed the overproduction of $\mathrm{sCD} 14$ in the supernatant of macrophages from stable adult patients with CF (29). However, plasma levels of sCD14 do not differ between stable adult CF patients and healthy subjects (Fig. 1A).

To elucidate the molecular mechanisms that underlie the production of the soluble form of CD14 in human CF macrophages, we studied several hypotheses based on the literature. It was reported that $\mathrm{sCD} 14$ could be generated by different mechanisms, including the endocytosis of mCD14, the cleavage of the GPI anchor by PI-PLC, direct proteolytic cleavage from the cell surface and neosynthesis.

To explore the neosynthesis hypothesis, we examined the regulation of CD14 production at the mRNA level in CF and non-CF macrophages. We found that CD14 mRNA levels were similar between CF and non-CF macrophages (Fig. 1B). Furthermore, pulse chase experiments with Click-IT® L- Azidohomoalanin showed no differences in neosynthesis of sCD14 between non$\mathrm{CF}$ and $\mathrm{CF}$ macrophages whereas we demonstrated an increase of total sCD14 production in supernatant of CF macrophages (Fig. 1C). Thus, neosynthesis can be ruled out as a mechanism. sCD14 may be formed by direct proteolytic cleavage from the cell surface. However, the inhibitors of metalloproteases (EDTA, Fig. 2A), cysteine proteases (e64d, Fig. 2D), aspartic proteases (pepstatin A, Fig. 2E) or serine proteases (aprotinin, Fig. 2F) did not influenced sCD14 production. Furthermore, the gene expression of the metalloproteases MMP-9 (Fig. 2B), MMP-12 (Supplemental Fig. 1A), ADAM-9, -10, -12, 17 (Supplemental Fig. 1B to 1E) and cathepsins B, D, F, K and S (Supplemental Fig. $1 F$ to $1 J$ ) in CF macrophages is decreased. Moreover, the latent form of the MMP-9 protein and supernatant MMP-9 activity, as measured by zymography, are decreased in CF vs. non-CF macrophages (Fig. 2C). The protease cleavage hypothesis is 
The main hypothesis concerning sCD14 generation is the cleavage of the GPI tail by PI-PLC. We investigated this hypothesis by exposing non-CF macrophages to PI-PLC $(1 \mathrm{U} / \mathrm{ml})$ with or without its inhibitor, U-73122 $(12.5 \mu \mathrm{M})$. We observed that PI-PLC significantly increased the production of sCD14 by non-CF macrophages and that this effect was inhibited by U-73122 (Fig. $3 A$ ). However, the treatment of CF macrophages with U-73122 did not inhibit the increased secretion of sCD14 into their supernatant (Fig. 3B). Furthermore, the expression of the PLC gene does not differ between non-CF and CF macrophages (Supplemental Fig. 1G). Indeed, PI-PLC participates in the production of $\mathrm{sCD} 14$ in non-CF macrophages but has no role in $\mathrm{sCD} 14$ overproduction from $\mathrm{CF}$ macrophages.

Cholesterol has been reported to increase sCD14 secretion through the endocytosis and subsequent cleavage of mCD14. Furthermore cholesterol is increased in CF macrophages (Fig. 4A). Thus, we investigated the effect of water-soluble cholesterol supplementation in non-CF macrophages. The results presented in Fig. $4 B$ show that $\mathrm{SCD} 14$ production by non-CF macrophages is increased by supplementation with water-soluble cholesterol (15 $\mu \mathrm{g} / \mathrm{ml})$. By modulating membrane lipid composition, cholesterol could be involved in the production of sCD14 in CF macrophages.

The fungal metabolite brefeldin A blocks forward protein transport between the ER and the Golgi complex but not retrograde transport (33). Incubation with brefeldin A decreased sCD14 secretion in non-CF and CF macrophages, implicating the secretory ER/Golgi pathway in sCD14

\section{Function of human recombinant sCD14 in human macrophages}

323 To evaluate the inflammatory role of sCD14 in human non-CF macrophages, we used human recombinant sCD14 (hr-sCD14), which did not affect the viability of the cells (data not shown).

We had to check the effect of human recombinant $\mathrm{sCD} 14$ on the NFkB activation, which is required for cytokine/chemokine production. In fact, the mean concentration of sCD14 in $\mathrm{CF}$ macrophage supernatants was $14.68 \mathrm{ng} / \mathrm{ml}$ per $2 \times 10^{6}$ cells/well (Fig. $3 B$ ), which corresponds to $220 \mathrm{ng} / \mathrm{ml}$ per $30 \times 10^{6}$ cells, in comparison to the mean level of sCD14 observed in non-CF 
macrophage supernatants, which was $2.35 \mathrm{ng} / \mathrm{ml}$ per 30x $10^{6}$ cells/well (Fig. 4B). Indeed, we used increasing concentrations of human recombinant $\mathrm{SCD} 14\left(1,10,100\right.$ and $500 \mathrm{ng} / \mathrm{ml}$ on $30 \times 10^{6}$ non-CF cells/well) to evaluate its inflammatory role in macrophages.

To determine whether sCD14 has an inflammatory effect, we investigated the production of proinflammatory cytokine/chemokine by non-CF macrophages exposed to sCD14. Treatment with sCD14 significantly increased IL-1 $\beta$, IL- 8 and TNF- $\alpha$ gene expressions at 6 hours and secreted levels at 24 hours in a dose-dependent manner (Fig. 5A and 5B). The effects on gene expression were maintained at 24 hours (Fig. 5A). These results show that sCD14 could participate in chronic inflammation by promoting pro-inflammatory cytokine/chemokine secretion. Furthermore, sCD14 potentiates LPS-induced cytokine/chemokine production by non-CF macrophages (Supplemental Fig. 2).

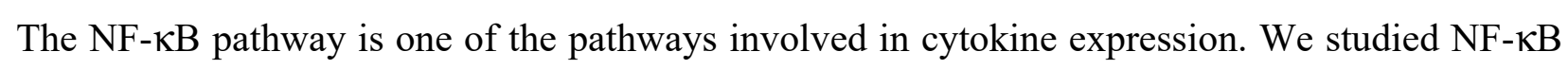
activation after sCD14 treatment in non-CF macrophages. The results showed the

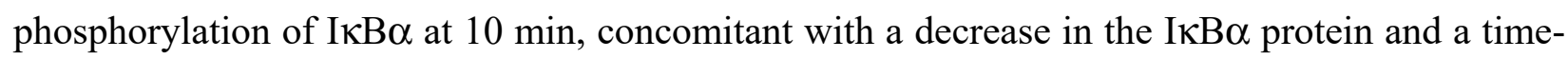
dependent translocation of the NFKB p65 subunit to the nucleus (Fig. 6A and 6B). Indeed, the NF- $\mathrm{kB}$ pathway is activated by $\mathrm{sCD} 14$ in non-CF macrophages. To determine whether this activation is related to the expression and secretion of inflammatory cytokines, we pretreated non-CF macrophages with an inhibitor of NF- $\mathrm{KB}$, Bay 11-7082. Bay 11-7082, which is a potential anti-inflammatory agent, is an irreversible inhibitor of IKK $\alpha$ and cytokine-inducible I $\mathrm{B} \alpha$ phosphorylation that does not affect constitutive phosphorylation (34). A significant decrease in IL-1 $\beta$, TNF- $\alpha$ and IL-8 gene expressions and secreted levels was observed with Bay 11-7082 (Fig. $6 C$ and $6 D$ ). These results show that the NF- $\mathrm{kB}$ pathway participates in the proinflammatory cytokine/chemokine production induced by non-CF macrophages sCD14 treatment.

Unlike other pro-inflammatory cytokines, IL-1 $\beta$ production is tightly regulated by a unique twosignal mechanism. The primary signal induces the expression of pro-IL-1 $\beta$ and is mediated in part by NF- $\mathrm{BB}$ activation. The secondary signal activates the NLR-subset inflammasome intracellular signaling complexes, which are composed of NLRs, pro-caspase 1, and the adaptor 
protein ASC. The formation of the inflammasome complex results in the proteolytic cleavage of pro-caspase 1 to yield active caspase 1, which in turn cleaves pro-IL-1 $\beta$, producing mature and active IL-1 $\beta$. To determine if caspase 1 could be involved in IL-1 $\beta$ processing in response to sCD14, we investigated caspase 1 expression and activation. Macrophage exposure to sCD14 induced early caspase 1 cleavage starting after $5 \mathrm{~min}$ through the early production of pro-caspase 1 and the appearance of cleaved caspase 1 (Fig. 7A). This cleavage is followed by the subsequent secretion of IL-1 $\beta$ by macrophages starting after $120 \mathrm{~min}$ (Fig. 7B). To investigate the involvement of caspase 1 in IL-1 $\beta$ secretion after sCD14 treatment, we pre-incubated non-CF macrophages with the caspase 1 specific inhibitor Z-WEHD-FMK. The caspase 1 inhibitor abolished IL-1 $\beta$ secretion by non-CF macrophages (Fig. 7C). All of these results showed that IL$1 \beta$ production in response to $\mathrm{sCD} 14$ involves the caspase 1 pathway.

Caspase 1 pathway activation requires a specific platform called the inflammasome complex. However, various inflammasome complexes are formed depending on the stimulus. Concerning 374 the inflammasome complex in macrophages, the most frequently involved stimuli are flagellin or LPS. We investigated the NLRC4 and NRLP3 inflammasome complexes by using RNA interference. The efficiency of transfection of NLRC4 siRNA and NLRP3 siRNA was assessed

377 via western blotting of the total protein fraction from non-CF macrophages. Specific siRNAs directed against NLRC4 and NLRP3 turned off NRLC4 and NLRP3 protein expression in macrophages, respectively (Fig. 8A and $8 B$ ). Furthermore, while transfection with NLRP3 siRNA or NLRC4 siRNA had no significant effect on IL-1 $\beta$ secretion, in macrophages treated with sCD14, transfection with each siRNA significantly decreases IL-1 $\beta$ secretion (Fig. 8C). These results suggested that both inflammasome platforms (NLRC4 and NLRP3) participate in the induction of IL-1 $\beta$ secretion in response to $\mathrm{SCD} 14$ exposure.

385 In view of the mechanisms described above, the TLR-4 receptor and its signaling pathways 386 should be involved in the effects induced by sCD14 in macrophages. To efficiently neutralize the 387 biological activity of sCD14, non-CF macrophages were pre-incubated with a CD14-neutralizing 388 antibody, resulting in decreased IL-8, TNF- $\alpha$ and IL-1 $\beta$ levels in the cell supernatants (Fig. 9). 389 Moreover, the pretreatment of non-CF macrophages with an antagonist of TLR-4 (LPS-RS) 
390 strongly inhibited the TNF- $\alpha$, IL-8 and IL-1 $\beta$ production induced by sCD14 (Fig. 9). Finally to 391 neutralize TLR4, non-CF macrophages were pre-incubated with a TLR4-neutralizing antibody, 392 resulting in decreased IL-8 and TNF- $\alpha$ levels in the cell supernatants. Treatment with sCD14 did 393 not modify the membrane expression of TLR-4, as measured by flow cytometry, showing that 394 TLR-4 is not endocytosed after activation (data not shown). In this context, TLR-4 should be 395 involved in the inflammatory effect of sCD14. 


\section{DISCUSSION}

398 Macrophages coordinate inflammatory responses by secreting cytokines and chemokines that are 399 responsible for diverse physiological effects that are important in the pathogenesis of CF and 400 result in chronic infection/inflammation (35-37).

In a previous study, we observed an increase in cytokine/chemokine production in $\mathrm{CF}$ 403 macrophage supernatants and particularly strong secretion of sCD14 (29). Elevated 404 concentrations of sCD14 were also found in serum from patients with bacterial infections $(38,39)$ or pneumonia (40), as well as in other chronic inflammatory diseases, such as lupus erythematosus (41). However, we did not observe elevated sCD14 levels in plasma from stable adult $\mathrm{CF}$ patients, showing that $\mathrm{SCD} 14$ is not a systemic marker in $\mathrm{CF}$, as previously observed in the plasma of children with CF (40).

410 It has been previously shown that sCD14 could be generated by several mechanisms, which 411 include neosynthesis, direct proteolytic cleavage from the cell surface, cleavage of the GPI 412 anchor by phospholipases and endocytosis/exocytosis (2, 3, 10-18). In our study, CD14 gene 413 expression was the same in CF and non-CF macrophages. Moreover, no neosynthesis of sCD14 414 was observed in CF macrophage. Indeed, the elevated sCD14 levels observed in CF macrophage 415 supernatants cannot be explained by an increase in gene expression and synthesis. Proteases, 416 metalloproteases and/or cathepsins have been demonstrated to be present in large amounts in CF 417 airways (42). However, the gene expression of MMPs, ADAMs as well as cathepsins is lower in 418 CF macrophages than in non-CF macrophages. Furthermore, MMP-9 and its activity are also 419 decreased in CF macrophage supernatants. Regarding these data, the origin of sCD14 in human 420 CF macrophages was not direct proteolytic cleavage from the cell surface, as reported previously, 421 explaining the increase in plasma sCD14 that occurs during sepsis (43). Cleavage of the GPI 422 anchor by phospholipases is also suggested to explain sCD14 release. In our study, PI-PLC 423 induced increased production of $\mathrm{sCD} 14$ in non-CF macrophage supernatants. The PI-PLC 424 inhibitor reversed this effect but not the sCD14 overproduction observed in CF macrophages. 425 Thus, PI-PLC participates in the production of sCD14 in non-CF macrophages but has no role in 426 sCD14 overproduction in CF macrophages. Finally, the hypothesis that involves the 
endocytosis/exocytosis of CD14 was considered. The depletion of cholesterol from the plasma membrane has been shown to affect endocytosis and protein sorting (44). As an example, cholesterol perturbation by filipin led to the redistribution of GPI-GFP from the cell surface to the Golgi complex (45), and the supplementation of the medium with cholesterol allowed the transport of secretory membrane proteins from the ER to the Golgi (46). In our study, cholesterol level is higher in CF than in non-CF macrophages and cholesterol supplementation in non-CF macrophages increased sCD14 secretion by macrophages. Furthermore, other work has shown that the inhibition of cholesterol synthesis by lovastatin decreased SCD14 production in RAW 264.7 macrophages (47). Endocytosis/exocytosis appears to be a suitable hypothesis because the use of brefeldin A to block forward transport between the ER and the Golgi complex decreases sCD14 secretion in CF macrophages.

It is well established that sCD14 alone is not sufficient to promote inflammation, except in cells that do not express $\mathrm{mCD} 14$, but the presence of $\mathrm{sCD} 14$ can enhance the sensitivity of monocytes and macrophages to LPS or lipopeptide by several orders of magnitude (48). In our study, we show that treatment with $\mathrm{sCD} 14$ alone enhances the induced inflammatory response and the effects of LPS by stimulating the secretion of IL- 8 , TNF- $\alpha$ and IL-1 $\beta$ in non-CF macrophages. However, one question remains to be answered: how can sCD14 induce the production of these inflammatory cytokines and chemokines?

Therefore, CD14 is assumed to function as a multi-ligand pattern recognition receptor by recognizing and binding to different PAMPs and DAMPs (49). In combination with the TLRs proteins, CD14 is an important mediator of innate immune responses to infection $(5,8)$. Membrane CD14 is a co-receptor for endotoxin through TLR-4 trans-membrane signaling, both at the cell surface and within the endosomal compartment. TLR-4 has been shown to contribute to the PAMP response of human cells, and its activation results in a pathway based on the activation of TIR-containing adaptor molecules: the rapid TIRAP/MyD88 pathway, which activates NF- $\mathrm{KB}$ and MAPK, resulting in the expression of pro-inflammatory cytokines and chemokines (50). In human monocyte-derived macrophages, sCD14 promoted the

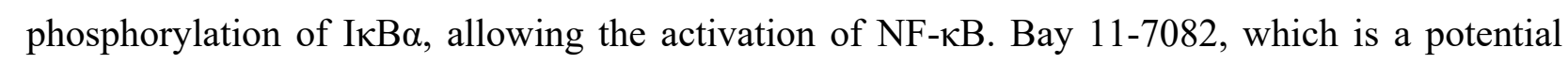
anti- inflammatory agent and an irreversible inhibitor of IKK $\alpha$ and IKB $\alpha$ phosphorylation, 
diminished sCD14-elicited IL-8, TNF- $\alpha$ and IL-1 $\beta$ expression and secretion, suggesting a role for

$459 \mathrm{NF \kappa B}$ signaling in sCD14-dependent macrophage inflammation. Furthermore, macrophage 460 activation with SCD14 induces the activation of pro-caspase 1, leading to the cleaved and active 461 form of caspase 1. Next, pro-IL-1 $\beta$ is cleaved by caspase 1 , and IL-1 $\beta$ mature is secreted in 462 macrophage supernatants; this effect is inhibited by Z-WEHD-FMK, which is a specific caspase 4631 inhibitor. The activation of caspase 1 involves inflammasome complex formation, which 464 requires NLRs. NLRs are pattern recognition receptors and play key roles in the regulation of the 465 innate immune response in cooperation with TLRs. Among the NLRs, NLRC4 and NLRP3 466 appear to be the most involved in this response. The infection of macrophages with several 467 Gram-negative bacteria, including Pseudomonas aeruginosa, which currently infects CF patients, 468 activates caspase 1 through NLRC4 (51). The activation of caspase 1 through NLRP3 is induced 469 by DAMPs, such as $\mathrm{K}^{+}$efflux, ATP via P2XR7, ROS, and cathepsin D from lysosome damage 470 (52). We turned off NRLC4 and NLRP3 protein expression using specific siRNAs directed 471 against NLRC4 or NLRP3. The treatment of macrophages with NLRP3 siRNA or NLRC4 472 siRNA abolished IL-1 $\beta$ secretion, suggesting that both inflammasome platforms (NLRC4 and 473 NLRP3) induce IL-1 $\beta$ secretion in response to sCD14 exposure. Altogether, our data suggest that 474 sCD14 acts as a DAMP in macrophages. In fact, extracellular sCD14 can bind membrane 475 proteins or phospholipids (53) that could be responsible for inflammatory cytokine production. 476 An anti-CD14 neutralizing antibody is able to inhibit the sCD14-induced synthesis of TNF- $\alpha$, IL4778 and IL-1 $\beta$. To explore the action of sCD14 via the TLR-4 receptor, we used a potent antagonist 478 of this receptor LPS-RS and an anti-TLR4 antibody, which decreases partly sCD14-induced 479 cytokine production in macrophages. Thus, part of the effect of sCD14 appears to be mediated by 480 the CD14/TLR-4 complex. However, further investigations are needed to completely understand 481 the molecular mechanisms involved in SCD14 signaling pathway in macrophages.

483 In conclusion, numerous mechanisms concerning the origin of sCD14 were considered in this 484 work, but in CF macrophages, the endocytosis/exocytosis process appears to be the main 485 mechanism involved in sCD14 production. We propose that the overproduction of sCD14 486 previously observed in macrophages from CF patients (29) should be considered to be a DAMP 487 that can induce pro-inflammatory cytokine/chemokine production independent of LPS. 
488 Moreover, sCD14 can also enhance the LPS response. Both of these effects are dependent on the 489 TLR-4/CD14 membrane complex, NF- $\mathrm{BB}$ and the inflammasome. The characterization of the 490 origin and inflammatory function of sCD14 presented in this paper is an important step in 491 understanding chronic infection/inflammation. Furthermore, this study provides a novel approach 492 to the development of anti-inflammatory therapeutics in $\mathrm{CF}$.

493 


\section{REFERENCES}

496 1. Bazil, V., Horejsi, V., Baudys, M., Kristofova, H., Strominger, J. L., Kostka, W., and Hilgert, I. (1986) Biochemical characterization of a soluble form of the 53-kDa monocyte surface antigen. Eur. J. Immunol. 16, 1583-1589

2. Haziot, A., Chen, S., Ferrero, E., Low, M. G., Silber, R., and Goyert, S. M. (1988) The

3. Simmons, D. L., Tan, S., Tenen, D. G., Nicholson-Weller, A., and Seed, B. (1989) Monocyte antigen CD14 is a phospholipid anchored membrane protein. Blood 73, 284-289

4. Wright, S. D. (1995) CD14 and innate recognition of bacteria. J. Immunol. 155, 6-8

5. Wright, S. D., Ramos, R. A., Tobias, P. S., Ulevitch, R. J., and Mathison, J. C. (1990) Science 249, 1431-1433

6. Schütt, C. (1999) CD14. Int. J. Biochem. Cell Biol. 31, 545-549

7. Gegner, J. A., Ulevitch, R. J., and Tobias, P. S. (1995) Lipopolysaccharide (LPS) Signal Transduction and Clearance. Dual roles for LPS binding protein and membrane CD14. J. Biol. Chem. 270, 5320-5325

8. Pugin, J., Heumann, D., Tomasz, A., Kravchenko, V. V., Akamatsu, Y., Nishijima, M., Glauser, M. P., Tobias, P. S., and Ulevitch, R. J. (1994) CD14 Is a pattern recognition receptor. Immunity 1, 509-516

9. Schiff, D. E., Kline, L., Soldau, K., Lee, J. D., Pugin, J., Tobias, P. S., and Ulevitch, R. J. (1997) Phagocytosis of gram-negative bacteria by a unique CD14-dependent mechanism. $J$. Leukoc. Biol. 62, 786-794

10. Bazil, V. and Strominger, J. L. (1991) Shedding as a mechanism of down-modulation of CD14 on stimulated human monocytes. J. Immunol. 147, 1567-1574

11. Bufler, P., Stiegler, G., Schuchmann, M., Hess, S., Krüger, C., Stelter, F., Eckerskorn, C., Schütt, C., and Engelmann, H. (1995) Soluble lipopolysaccharide receptor (CD14) is released via two different mechanisms from human monocytes and CD14 transfectants. Eur. J. Immunol. 25, 604-610 
12. Durieux, J.-J., Vita, N., Popescu, O., Guette, F., Calzada-Wack, J., Munker, R., Schmidt, R. E., Lupker, J., Ferrara, P., Ziegler-Heitbrock, H. W. L., and Labeta, M. O. (1994) The two soluble forms of the lipopolysaccharide receptor, CD14: Characterization and release by normal human monocytes. Eur. J. Immunol. 24, 2006-2012

13. Stelter, F., Pfister, M., Bernheiden, M., Jack, R. S., Bufler, P., Engelmann, H., and Schütt, C. (1996) The Myeloid Differentiation Antigen CD14 is N- and O-Glycosylated. Eur. J. Biochem. 236, 457-464

14. Thieblemont, N. and Wright, S. D. (1999) Transport of bacterial lipopolysaccharide to the Golgi apparatus. J. Exp. Med. 190, 523-534

15. Kirkland, T. N. and Viriyakosol, S. (1998) Structure-function analysis of soluble and membrane-bound CD14. Prog. Clin. Biol. Res. 397, 79-87

16. Bazil, V., Baudys, M., Hilgert, I., Stefanová, I., Low, M. G., Zbrozek, J., and Horejsí, V. (1989) Structural relationship between the soluble and membrane-bound forms of human monocyte surface glycoprotein CD14. Mol. Immunol. 26, 657-662

17. Coyne, C. P., Howell, T., Smodlaka, H., Willetto, C., Fenwick, B. W., and Chenney, E. (2002) Alterations in membrane-associated CD14 expression and the simultaneous liberation of soluble CD14 fragment in adherent macrophages mediated by a leukocyte carboxyl/aspartate protease. J. Endotoxin Res. 8, 273-283

18. Labeta, M. O., Durieux, J.-J., Fernandez, N., Herrmann, R., and Ferrara, P. (1993) Release from a human monocyte-like cell line of two different soluble forms of the lipopolysaccharide receptor, CD14. Eur. J. Immunol. 23, 2144-2151

19. Haziot, A., Rong, G. W., Bazil, V., Silver, J., and Goyert, S. M. (1994) Recombinant soluble CD14 inhibits LPS-induced tumor necrosis factor-alpha production by cells in whole blood. J. Immunol. 152, 5868-5876

20. Schütt, C., Schilling, T., and Krüger, C. (1991) sCD14 prevents endotoxin inducible oxidative burst response of human monocytes. Allerg. Immunol. (Leipz.) 37, 159-164

21. Tapping, R. I. and Tobias, P. S. (2000) Soluble CD14-mediated cellular responses to lipopolysaccharide. Chem. Immunol. 74, 108-121

22. Opal, S. M., Scannon, P. J., Vincent, J.-L., White, M., Carroll, S. F., Palardy, J. E., Parejo, N. A., Pribble, J. P., and Lemke, J. H. (1999) Relationship between Plasma Levels of 
Lipopolysaccharide (LPS) and LPS-Binding Protein in Patients with Severe Sepsis and Septic Shock. J. Infect. Dis. 180, 1584-1589

23. Salomao, R., Brunialti, M. K. C., Rapozo, M. M., Baggio-Zappia, G. L., Galanos, C., and Freudenberg, M. (2012) Bacterial sensing, cell signaling, and modulation of the immune response during sepsis. Shock Augusta Ga 38, 227-242

24. Martin, T. R., Ruhenfeld, G., Steinberg, K. P., Hudson, L. D., Raghu, G., Moriarty, A. M., Leturcq, D. J., Tobias, P. S., and Ulevitch, R. J. (1994) ENdotoxin, endotoxin-binding protein, and soluble cd14 are present in bronchoalveolar lavage fluid of patients with adult respiratory distress syndrome. Chest $105,55 \mathrm{~S}-56 \mathrm{~S}$

25. Dessing, M. C., Knapp, S., Florquin, S., de Vos, A. F., and van der Poll, T. (2007) CD14 Facilitates Invasive Respiratory Tract Infection by Streptococcus pneumoniae. Am. J. Respir. Crit. Care Med. 175, 604-611

26. Ratner, D. and Mueller, C. (2012) Immune Responses in Cystic Fibrosis. Am. J. Respir. Cell Mol. Biol. 46, 715-722

27. Cifani, N., Pompili, B., Anile, M., Patella, M., Diso, D., Venuta, F., Cimino, G., Quattrucci, S., Di Domenico, E. G., Ascenzioni, F., and Porto, P. D. (2013) Reactive-Oxygen-SpeciesMediated P. aeruginosa Killing Is Functional in Human Cystic Fibrosis Macrophages. PLoS ONE 8, e71717

28. Del Porto, P., Cifani, N., Guarnieri, S., Di Domenico, E. G., Mariggiò, M. A., Spadaro, F., Guglietta, S., Anile, M., Venuta, F., Quattrucci, S., and Ascenzioni, F. (2011) Dysfunctional CFTR Alters the Bactericidal Activity of Human Macrophages against Pseudomonas aeruginosa. PLOS ONE 6, e19970

29. Simonin-Le Jeune, K., Le Jeune, A., Jouneau, S., Belleguic, C., Roux, P.-F., Jaguin, M., Dimanche-Boitre, M.-T., Lecureur, V., Leclercq, C., Desrues, B., Brinchault, G., Gangneux, J.-P., and Martin-Chouly, C. (2013) Impaired Functions of Macrophage from Cystic Fibrosis Patients: CD11b, TLR-5 Decrease and sCD14, Inflammatory Cytokines Increase. PLOS ONE 8, e75667

30. Bellis, G., Lemonnier, L., and Sponga, M. (2012) Registre Français de la Mucoviscidose.

31. Grevenynghe, J. van, Rion, S., Ferrec, E. L., Vee, M. L., Amiot, L., Fauchet, R., and Fardel, O. (2003) Polycyclic Aromatic Hydrocarbons Inhibit Differentiation of Human Monocytes into Macrophages. J. Immunol. 170, 2374-2381 
32. Martin-Chouly, C. A. E., Astier, A., Jacob, C., Pruniaux, M.-P., Bertrand, C., and Lagente, V. (2004) Modulation of matrix metalloproteinase production from human lung fibroblasts by type 4 phosphodiesterase inhibitors. Life Sci. 75, 823-840

33. Miller, S., G., Carnell, L., and Moore, H.-P., H. (1992) Post-Golgi membrane traffic: brefeldin A inhibits export from distal Golgi compartments to the cell surface but not recycling. J. Cell Biol. 118, 267-283

34. Pierce, J. W., Schoenleber, R., Jesmok, G., Best, J., Moore, S. A., Collins, T., and Gerritsen, M. E. (1997) Novel Inhibitors of Cytokine-induced I B Phosphorylation and Endothelial Cell Adhesion Molecule Expression Show Anti-inflammatory Effects in Vivo. J. Biol. Chem. 272, 21096-21103

35. Douglas, T. A., Brennan, S., Gard, S., Berry, L., Gangell, C., Stick, S. M., Clements, B. S., and Sly, P. D. (2009) Acquisition and eradication of P. aeruginosa in young children with cystic fibrosis. Eur. Respir. J. 33, 305-311

36. Eickmeier, O., Huebner, M., Herrmann, E., Zissler, U., Rosewich, M., Baer, P. C., Buhl, R., Schmitt-Grohé, S., Zielen, S., and Schubert, R. (2010) Sputum biomarker profiles in cystic fibrosis (CF) and chronic obstructive pulmonary disease (COPD) and association between pulmonary function. Cytokine 50, 152-157

37. Tang, A., Sharma, A., Jen, R., Hirschfeld, A. F., Chilvers, M. A., Lavoie, P. M., and Turvey, S. E. (2012) Inflammasome-Mediated IL-1 $\beta$ Production in Humans with Cystic Fibrosis. PLOS ONE 7, e37689

38. Lin, B., Noring, R., Steere, A. C., Klempner, M. S., and Hu, L. T. (2000) Soluble CD14 Levels in the Serum, Synovial Fluid, and Cerebrospinal Fluid of Patients with Various Stages of Lyme Disease. J. Infect. Dis. 181, 1185-1188

39. Nockher, W. A., Wick, M., and Pfister, H.-W. (1999) Cerebrospinal fluid levels of soluble CD14 in inflammatory and non-inflammatory diseases of the CNS: upregulation during bacterial infections and viral meningitis. J. Neuroimmunol. 101, 161-169

40. Marcos, V., Latzin, P., Hector, A., Sonanini, S., Hoffmann, F., Lacher, M., Koller, B., Bufler, P., Nicolai, T., Hartl, D., and Griese, M. (2010) Expression, regulation and clinical significance of soluble and membrane CD14 receptors in pediatric inflammatory lung diseases. Respir. Res. 11, 32 
41. Egerer, K., Feist, E., Rohr, U., Pruss, A., Burmester, G. R., and Dörner, T. (2000) Increased serum soluble CD14, ICAM-1 and E-selectin correlate with disease activity and prognosis in systemic lupus erythematosus. Lupus 9, 614-621

42. Le-Barillec, K., Si-Tahar, M., Balloy, V., and Chignard, M. (1999) Proteolysis of monocyte CD14 by human leukocyte elastase inhibits lipopolysaccharide-mediated cell activation. $J$. Clin. Invest. 103, 1039-1046

43. Arai, Y., Mizugishi, K., Nonomura, K., Naitoh, K., Takaori-Kondo, A., and Yamashita, K. (2015) Phagocytosis by human monocytes is required for the secretion of presepsin. $J$. Infect. Chemother. 21, 564-569

44. Ikonen, E. (2001) Roles of lipid rafts in membrane transport. Curr. Opin. Cell Biol. 13, $470-477$

45. Nichols, B. J., Kenworthy, A. K., Polishchuk, R. S., Lodge, R., Roberts, T. H., Hirschberg, K., Phair, R. D., and Lippincott-Schwartz, J. (2001) Rapid Cycling of Lipid Raft Markers between the Cell Surface and Golgi Complex. J. Cell Biol. 153, 529-542

46. Miwako, I., Yamamoto, A., Kitamura, T., Nagayama, K., and Ohashi, M. (2001) Cholesterol requirement for cation-independent mannose 6-phosphate receptor exit from multivesicular late endosomes to the Golgi. J. Cell Sci. 114, 1765-1776

47. Frey, T. and De Maio, A. (2007) Increased Expression of CD14 in Macrophages after Inhibition of the Cholesterol Biosynthetic Pathway by Lovastatin. Mol. Med. 13, 592-604

48. Jersmann, H. P. (2005) Time to abandon dogma: CD14 is expressed by non-myeloid lineage cells. Immunol. Cell Biol. 83, 462-467

49. Schmitz, G. and Orsó, E. (2002) CD14 signalling in lipid rafts: new ligands and coreceptors. Curr. Opin. Lipidol. 13, 513-521

50. Dentener, M. A., Bazil, V., Asmuth, E. J. V., Ceska, M., and Buurman, W. A. (1993) Involvement of CD14 in lipopolysaccharide-induced tumor necrosis factor-alpha, IL-6 and IL-8 release by human monocytes and alveolar macrophages. J. Immunol. 150, 2885-2891

51. Franchi, L., Eigenbrod, T., Muñoz-Planillo, R., and Nuñez, G. (2009) The Inflammasome: A Caspase-1 Activation Platform Regulating Immune Responses and Disease Pathogenesis. Nat. Immunol. 10, 241

52. Yu, H. B. and Finlay, B. B. (2008) The Caspase-1 Inflammasome: A Pilot of Innate Immune Responses. Cell Host Microbe 4, 198-208 
646 53. Yu, B., Hailman, E., and Wright, S. D. (1997) Lipopolysaccharide binding protein and 647 soluble CD14 catalyze exchange of phospholipids. J. Clin. Invest. 99, 315-324

648

649 


\section{AUTHOR CONTRIBUTIONS}

651

652 M. Lévêque, K. Simonin-Le Jeune and C. Martin-Chouly designed research; M. Lévêque, K. 653 Simonin-Le Jeune and C. Martin-Chouly performed the experiments; S; Moulis, C. Belleguic, G. 654 Brinchault, B. Desrues, S. Le Trionnaire, J-P. Gangneux and S. Jouneau contributed new reagents 655 or analytic tools; M. Lévêque and C. Martin-Chouly analyzed data; M. Lévêque, M-T. 656 Dimanche-Boitrel and C. Martin-Chouly wrote the paper. 


\section{ACKNOWLEDGEMENTS}

659

660 We would particularly like to thank Mrs. Laurence Hiard and the nurses Mrs. Marie-Thérèse 661 Jousseaume and Mrs. Isabelle Berhault at CRCM (Centre de Ressources et de Compétences pour 662 la Mucoviscidose) from Rennes University Hospital. This work is supported by the Cystic 663 Fibrosis French Foundation "Vaincre La Mucoviscidose" (RF20130500807).

664 
Figure 1. Soluble CD14 level in plasma and CD14 gene expression in macrophages. $(A)$ sCD14 levels in plasma from healthy subjects (non-CF, $n=8)$ and CF patients $(n=12$, patients 1 12, supplemental Table 1), as measured using an ELISA assay. Each symbol represents a single individual, and the line is the mean. (B) CD14 gene expression in non-CF macrophages $(n=14)$ and CF macrophages ( $n=15$, patients 6, 13-26; supplemental Table I). mRNA levels were determined by RT-qPCR (supplemental Table 2). Each symbol represents a single individual, and the line is the mean. (C) Neosynthesis (O.D.) and total (pg/ml) sCD14 in macrophage supernatant from healthy subjects (non-CF, $n=5)$ and CF patients ( $n=5$, patients $6,13-16$, supplemental Table 1). The data are shown as the mean \pm SEM. Mann-Whitney test: $* \mathrm{p}<0.05$ vs. non-CF macrophages.

Figure 2. Altered CF macrophage phenotype is associated with markedly decreased expression and activity of proteases. $(A)$ The inhibition of metalloproteases by EDTA $(0.1 \mathrm{mM}$, expression is reduced in CF macrophages ( $n=6$, patients 6, 13-16 and 32, supplemental Table 1) vs. non-CF macrophages $(n=9)$. Gene expression was determined by RT-qPCR (supplemental Table 2). (C) In a representative gelatin zymogram, latent MMP-9 (92 kDa) is observed based on proteolysis areas, which appeared as clear bands against a dark background. After scanning the gels, both the surface and intensity of the lysis bands were analyzed by densitometry (bar graph) and showed decreased expression of latent MMP-9 in CF macrophages $(n=12$, patients 33-44, supplemental Table 1) vs. non-CF macrophages $(n=11)$. The results were expressed vs. the relative latent MMP-9 intensity observed in the supernatant of non-CF macrophages. $(D, E, F)$ The inhibition of cysteine proteases by $\operatorname{e} 64 \mathrm{~d}(D, 1 \mu \mathrm{M}, 24$ hours, $\mathrm{n}=10)$, aspartic proteases by pepstatin $\mathrm{A}(E, 1 \mu \mathrm{M}, 24$ hours, $\mathrm{n}=4)$ and serine proteases by aprotinin $(0.3 \mu \mathrm{g} / \mathrm{ml}, 24$ hours, $\mathrm{n}=9)$ did not influenced sCD14 secretion in non-CF macrophages. The data are shown as the mean \pm 693 SEM. Mann-Whitney test: $* \mathrm{p}<0.05$ and $* * \mathrm{p}<0.01$ vs. non-CF macrophages.

Figure 3. PI-PLC increases sCD14 production in non-CF macrophages. sCD14 levels were measured in supernatants from macrophages using an ELISA assay. (A) PI-PLC (1 U/ml, 2 

of PI-PLC by U-73122 (12.5 $\mu \mathrm{M}, 1$ hour pretreatment) inhibited PI-PLC-induced sCD14 secretion in non-CF macrophages $(n=7)$.

(B) U-73122 (12.5 $\mu \mathrm{M}, 24$ hours) did not prevent spontaneous sCD14 production by CF macrophages ( $n=6$, patients $43,45-49$; supplemental Table 1). The data are shown as the mean \pm SEM. Ratio Student's t-test: \#\# $p<0.01$ vs. untreated nonCF macrophages; ** $\mathrm{p}<0.01$ vs. PI-PLC-treated non-CF macrophages.

702

703

Figure 4. Impact of intracellular protein transport on sCD14 production by non-CF and CF macrophages. (A) Free cholesterol level is increased in CF ( $n=8$, patients 43, 47, 50-55; supplemental Table 1) vs non-CF $(n=4)$ macrophages $(B)$ Water-soluble cholesterol (15 $\mu \mathrm{g} / \mathrm{ml} ; 24$ hours) significantly increases $\mathrm{sCD} 14$ production by non-CF macrophages $(n=5)$. $(C)$ Brefeldin $\mathrm{A}$ (Bref A; $100 \mathrm{ng} / \mathrm{ml} ; 3 \mathrm{~h}$ ) significantly decreased $\mathrm{sCD} 14$ production by non-CF $(n=5)$ and $\mathrm{CF}$

708 ( $n=5$, patients 56-60; supplemental Table 1) macrophages. Levels in the supernatants were measured using an ELISA assay. The data are shown as the mean \pm SEM. Mann-Whitney test: ** $\mathrm{p}<0.01$ vs. non-CF macrophages. Ratio Student's t-test: \# $\mathrm{p}<0.05$ vs. untreated non-CF macrophages and $\S \mathrm{p}<0.05$ vs. untreated CF macrophages.

Figure 5. Human recombinant sCD14 induces the expression and secretion of proinflammatory cytokines in non-CF macrophages. (A) IL-1 $\beta$, IL-8 and TNF- $\alpha$ mRNA expression was quantified by RT-qPCR in non-CF macrophages treated with hr-sCD14 (100 and $500 \mathrm{ng} / \mathrm{ml}, 6$ hours and 24 hours). The data are shown as the mean \pm SEM of four and five independent experiments for 6 hours and 24 hours, respectively. (B) IL-1 $\beta$, IL-8 and TNF- $\alpha$ release were measured by using an ELISA assay in supernatants from non-CF macrophages treated with hr-sCD14 ( 1 to $500 \mathrm{ng} / \mathrm{ml}, 24$ hours). The data are shown as the mean $\pm \mathrm{SEM}$ ( $n=6$ $11, n=4$ and $n=3-6$ for IL-1 $\beta$, IL-8 and TNF- $\alpha$, respectively). Ratio Student's t-test: * $\mathrm{p}<0.05$; ** $\mathrm{p}<0.01 ; * * * \mathrm{p}<0.001$ and $* * * * \mathrm{p}<0.0001$ vs. untreated macrophages. cytokines in non-CF macrophages. $(A)$ Cytosol $\mathrm{P}-\mathrm{I} \kappa \mathrm{B} \alpha$ and $\mathrm{I} \kappa \mathrm{B} \alpha$ expression were determined 
by Western blotting of the total protein fraction from non-CF macrophages treated with hr-sCD14

727 (500 ng/ml, 0 to $60 \mathrm{~min}$, representative blot of three independent experiments). Equal protein loading was controlled via HSC-70 detection. (B) NFאB p65 activation was measured using an assay in non-CF macrophages that were treated or not treated with hr-sCD14 $(n=5 ; 500 \mathrm{ng} / \mathrm{ml}, 24$ hours). A positive control was used to establish the result. (C) IL-1 $\beta$, IL-8 and TNF- $\alpha$ gene expression was analyzed by RT-qPCR in non-CF macrophages treated or not treated with hr$\mathrm{sCD} 14$ (500 ng/ml, 6 hours) in the absence and presence of an NF- $\mathrm{kB}$ inhibitor (Bay 11-7082, 10 $\mu \mathrm{M}, 1$ hour pretreatment, $n=5)(D)$ IL- $1 \beta$, IL-8 and TNF- $\alpha$ protein expression were quantified using an ELISA assay in non-CF macrophages that were treated or not treated with hr-sCD14 (500 ng/ml, 24 hours) in the absence or presence of Bay 11-7082 (1 and $10 \mu \mathrm{M}, 1$ hour pretreatment; $n=4, n=4$ and $n=5$ for IL- $1 \beta$, IL- 8 and TNF- $\alpha$, respectively). The data are shown as the mean \pm SEM. Ratio Student's t-test: * $\mathrm{p}<0.05$ and $* * * \mathrm{p}<0.001$ vs. untreated macrophages; \# $\mathrm{p}<0.05$ and \#\# $\mathrm{p}<0.01$ vs. hr-sCD14-treated macrophages.

Figure 7. Caspase-1 is involved in the sCD14-induced production of IL-1 $\beta$ in non-CF macrophages. (A) Pro-caspase 1 and caspase 1 expression were determined by Western blotting analysis of the total protein fraction from non-CF macrophages treated with hr-sCD14 (500 $\mathrm{ng} / \mathrm{ml}, 0$ to $60 \mathrm{~min}$, a representative blot of three independent experiments). (B) IL-1 $\beta$ secretion was measured using an ELISA assay in supernatants from non-CF macrophages treated with hr$\mathrm{sCD} 14(500 \mathrm{ng} / \mathrm{ml}, 0$ to $1440 \mathrm{~min})$. The data are shown as the mean $\pm \mathrm{SEM}(n=7)$. (C) IL-1 $\beta$ secretion was measured using an ELISA assay in supernatants from non-CF macrophages treated or not treated with hr-sCD14 (500 ng/ml, 24 hours) in the absence or presence of the caspase 1 inhibitor Z-WEHD-FMK (1 to $30 \mu \mathrm{M}$, 1-hour pretreatment). The data are shown as the mean \pm $\operatorname{SEM}(n=4)$. Ratio Student's t-test: $* \mathrm{p}<0.05$ and $* * \mathrm{p}<0.01$ vs. untreated macrophages; $\# \mathrm{p}<0.05$

Figure 8. NLRC4 and NLRP3 inflammasome pathways are involved in IL-1 $\beta$ secretion in 753 non-CF macrophages treated with hr-sCD14. ( $A$ and $B$ ) The efficiency of transfection with 754 NLRC4 siRNA or NLRP3 siRNA was assessed by Western blotting of the total protein fraction from non-CF macrophages. The bar graph shows the results of densitometric analysis $(n=6)$. The 
756 results were expressed vs. the relative intensity observed in Control siRNA-treated non-CF 757 macrophages. (C) IL-1 $\beta$ release was measured by ELISA in supernatants from non-CF 758 transfected macrophages that were treated or not treated with hr-sCD14 (500 ng/ml, 24 hours; $759 n=6)$. The data are shown as the mean \pm SEM. Ratio Student's t-test: $* * p<0.01$ vs. siControl760 treated macrophages; \#\# $\mathrm{p}<0.01$ vs. untreated macrophages; $\S \mathrm{p}<0.05$ and $\S \S \mathrm{p}<0.01$ vs. hr761 sCD14-treated macrophages.

762

763 Figure 9. sCD14-induced cytokine release by non-CF macrophages is reversed by 764 antagonists that target CD14 or TLR-4. IL-1 $\beta$, IL-8 and TNF- $\alpha$ secretion was measured by 765 ELISA in supernatants from non-CF macrophages that were treated or not treated with hr-sCD14 766 (500 ng/ml, 24 hours) in the absence or presence of an anti-CD14 neutralizing antibody (CD14$767 \mathrm{ab}, 10 \mu \mathrm{g} / \mathrm{ml}$, 1-hour pretreatment), a TLR-4 antagonist (LPS-RS, $2 \mu \mathrm{g} / \mathrm{ml}$, 1-hour pretreatment), 768 an anti-TLR4 neutralizing antibody (TLR4-ab, $10 \mu \mathrm{g} / \mathrm{ml}$, 1-hour pretreatment) or the IgG2a 769 control $(10 \mu \mathrm{g} / \mathrm{ml}, 1$ hour pretreatment). The data are shown as the mean \pm SEM $(n=3-6, n=3-6$ 770 and $n=3-6$ for IL-1 $\beta$, IL-8 and TNF- $\alpha$, respectively). Ratio Student's t-test: * $\mathrm{p}<0.05$ and ** $771 \mathrm{p}<0.01$ vs. hr-sCD14-treated macrophages. 
A

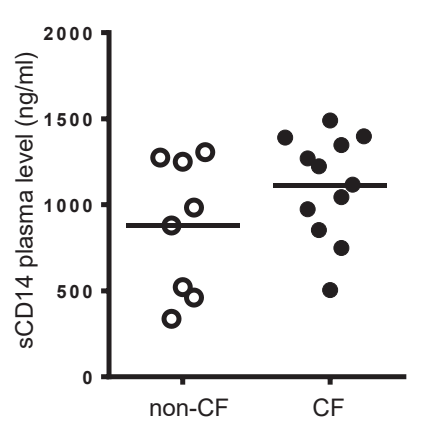

B

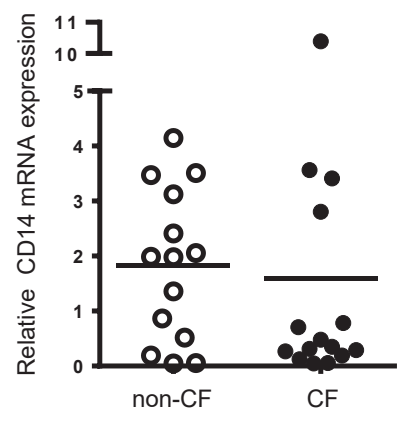

C

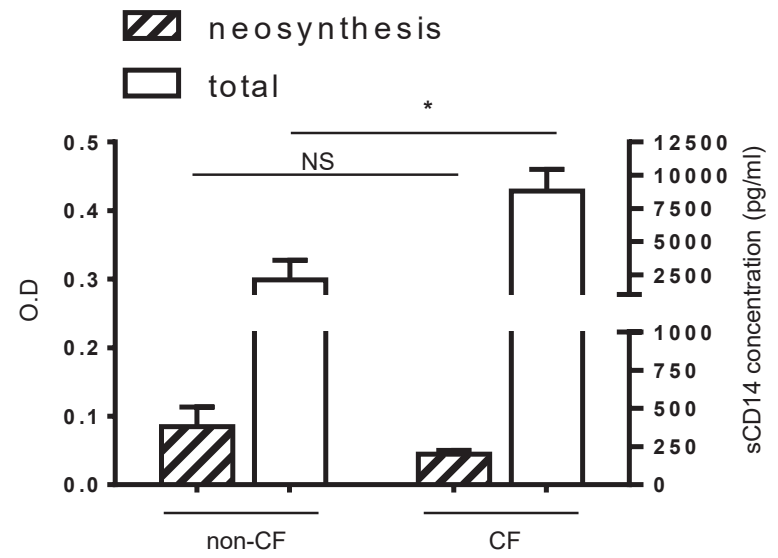


Figure 2

Fig 2

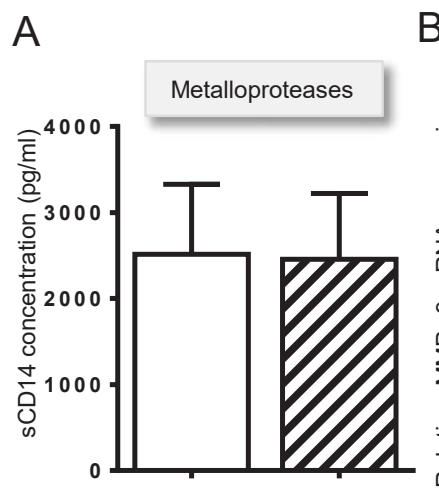

EDTA

B

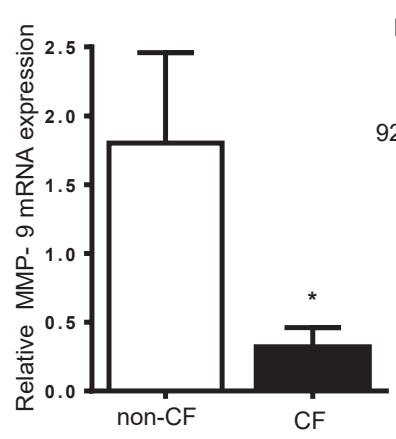

E

D

Cysteine proteases

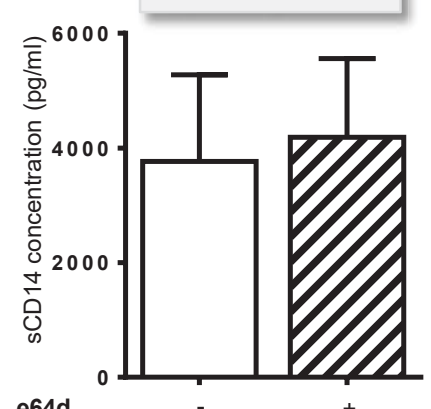

C
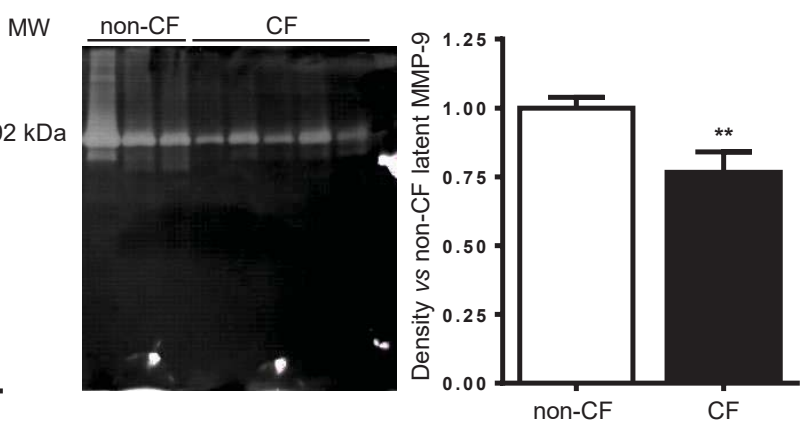

F

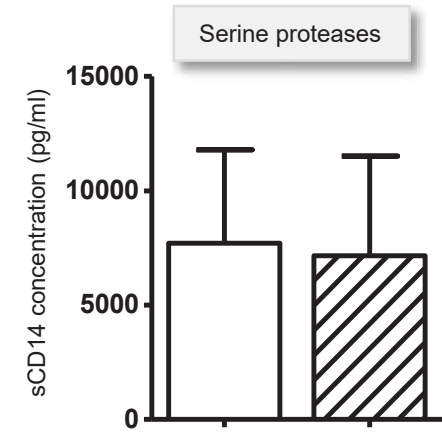

aprotinin

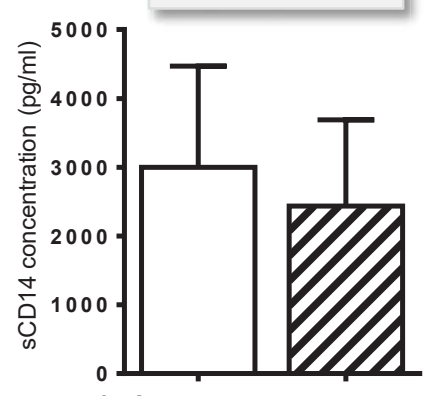

pepstatin A

$+$ 
Figure 3

Fig 3

A

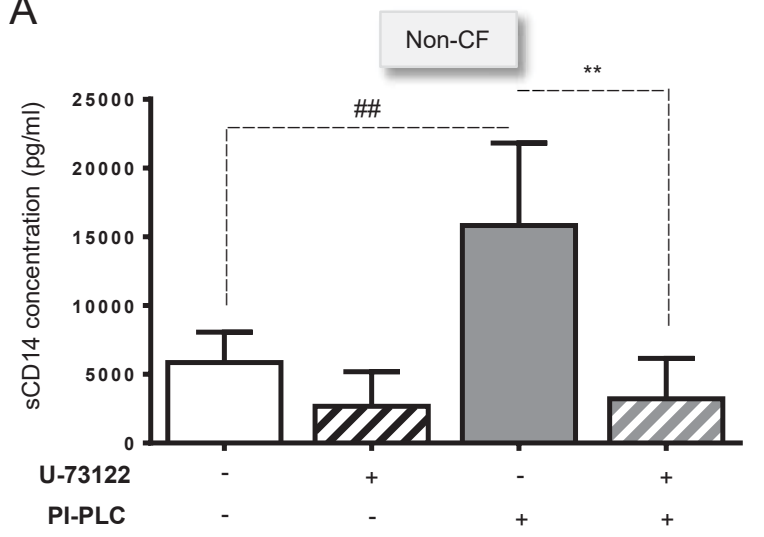

B

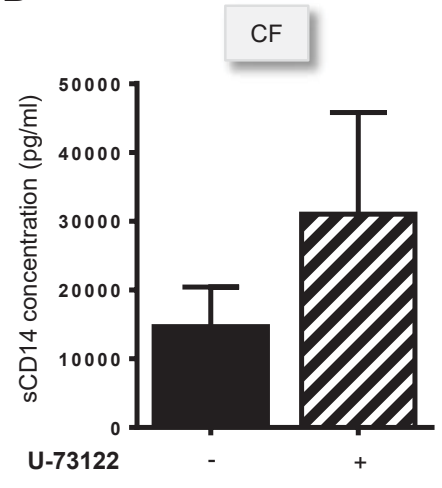


Figure 4

Fig 4

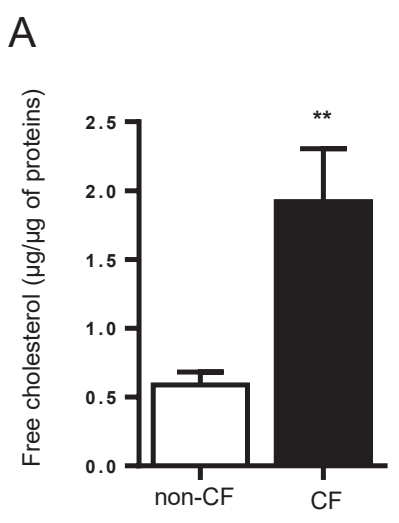

B

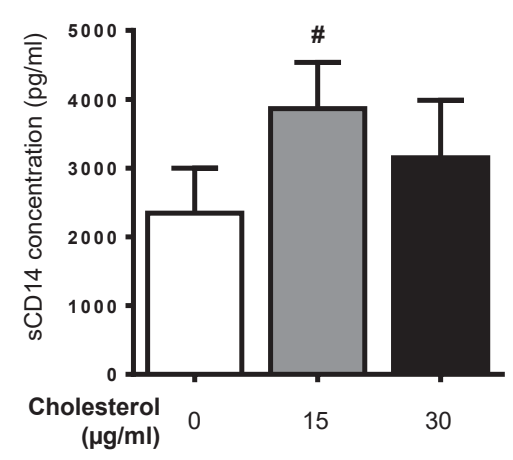

C

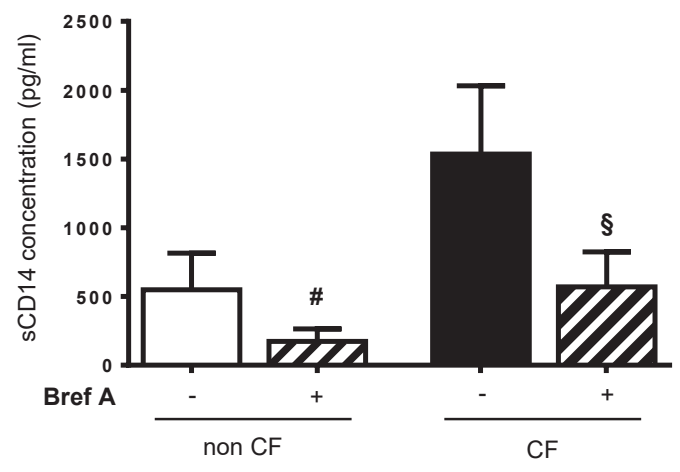


A

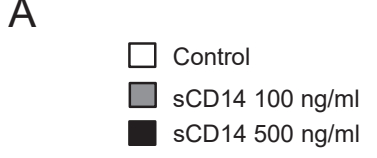

B
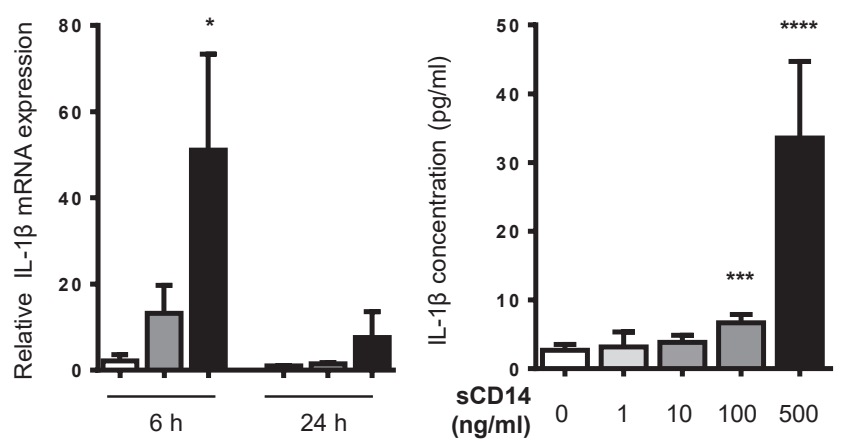

$\square$ Control

$\square$ sCD14 100 ng/ml

sCD14 $500 \mathrm{ng} / \mathrm{ml}$
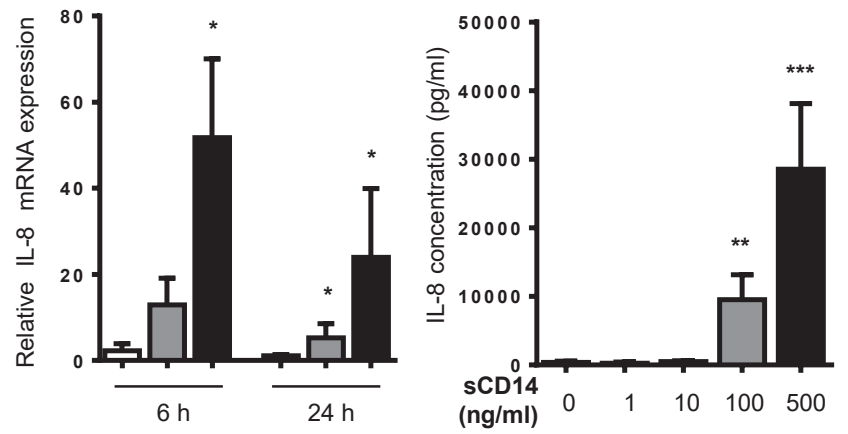

$\square$ Control

$\square$ sCD14 $100 \mathrm{ng} / \mathrm{ml}$

sCD14 $500 \mathrm{ng} / \mathrm{ml}$
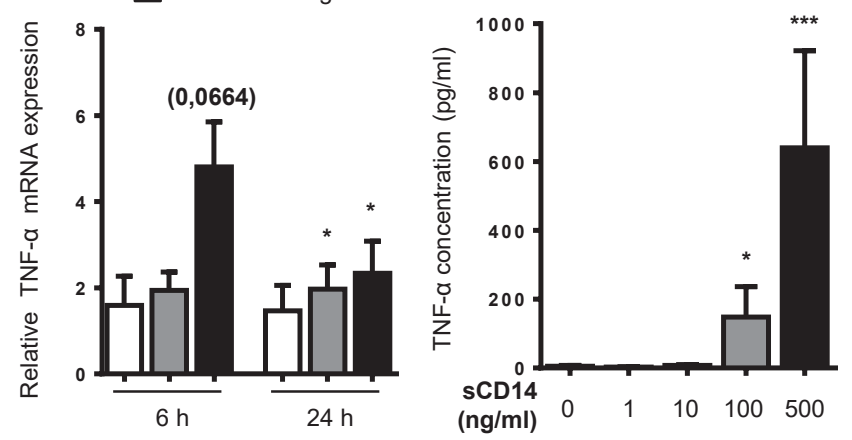
A

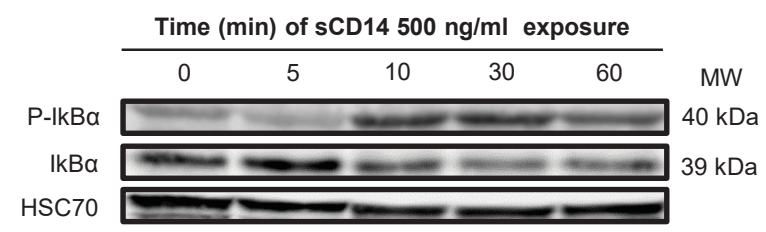

B

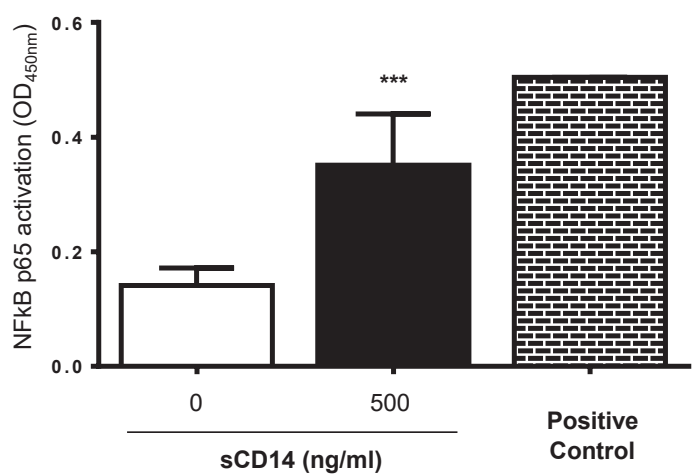

C

D
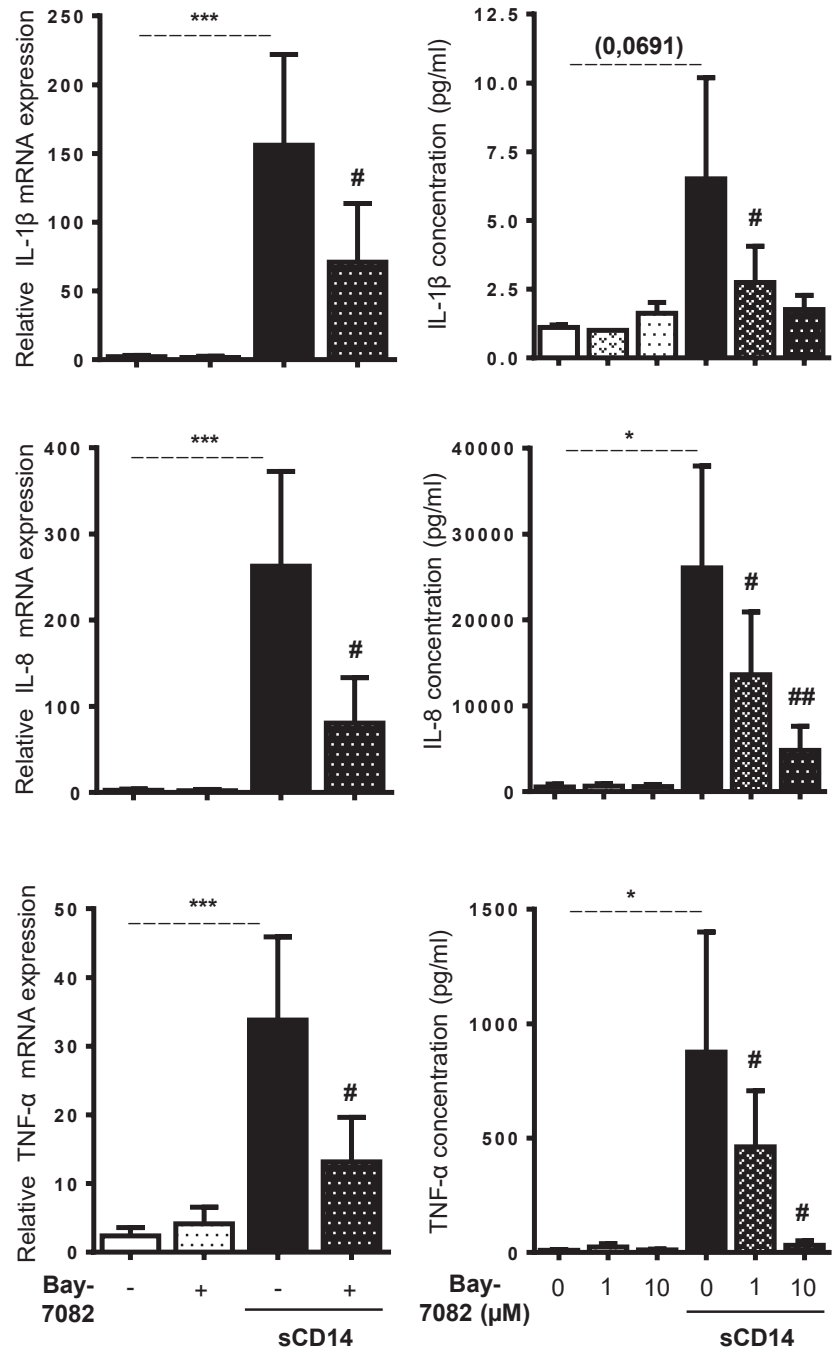


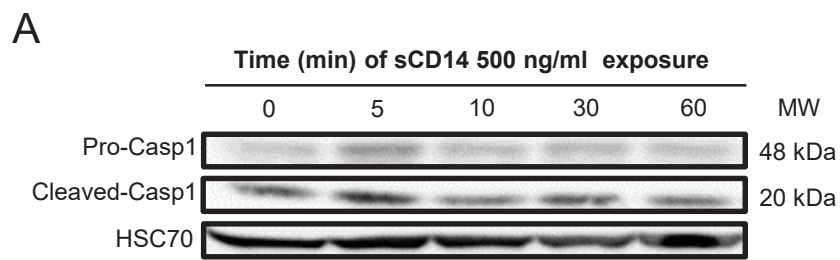

B
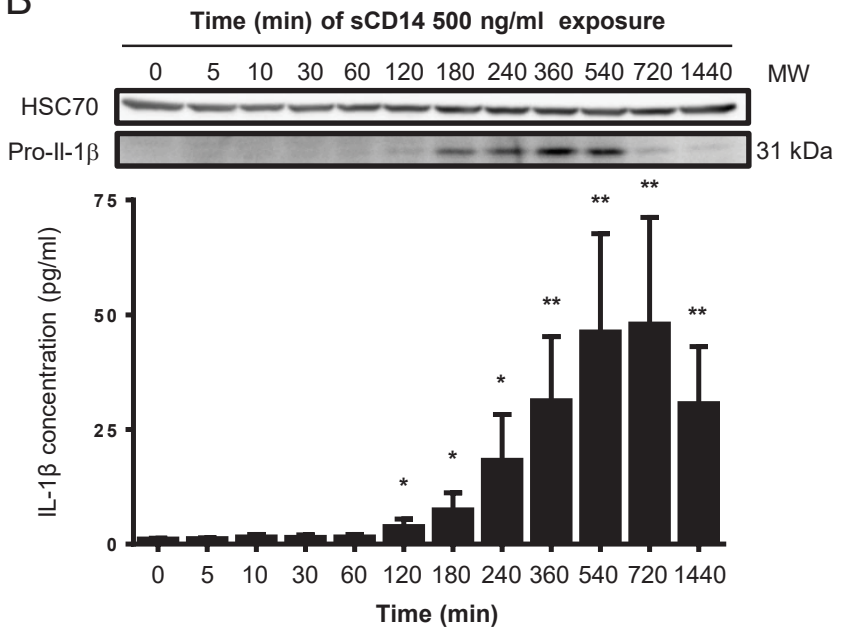

C

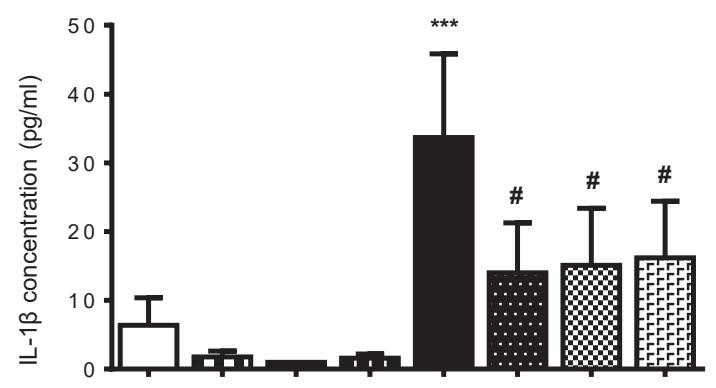

Z-WEHD-FMK

$(\mu \mathrm{M})$

$30 \quad 0$

\begin{tabular}{lrr}
1 & 10 & 30 \\
\hline
\end{tabular} 
A

B

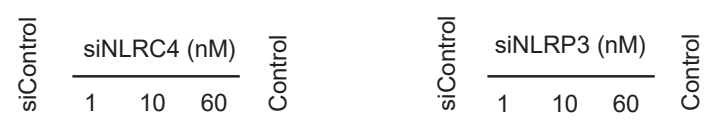

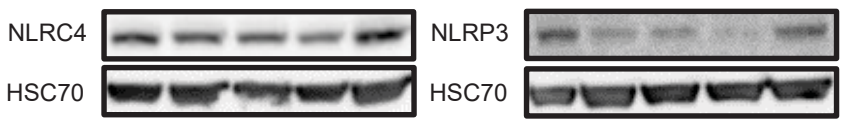
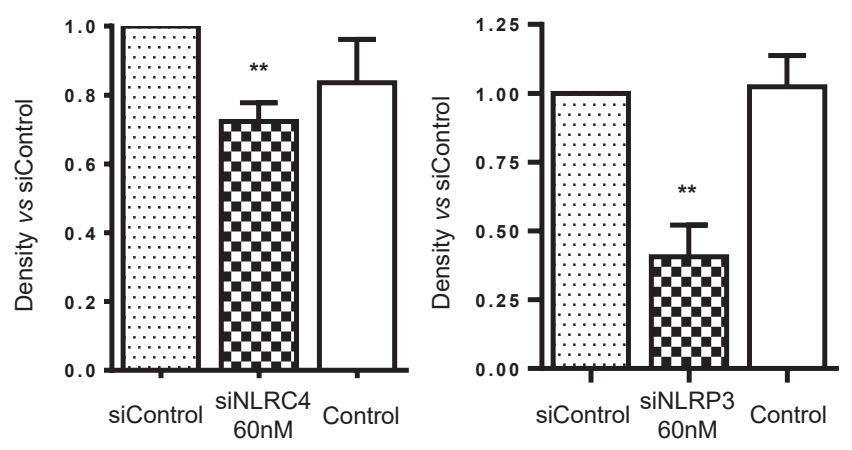

C

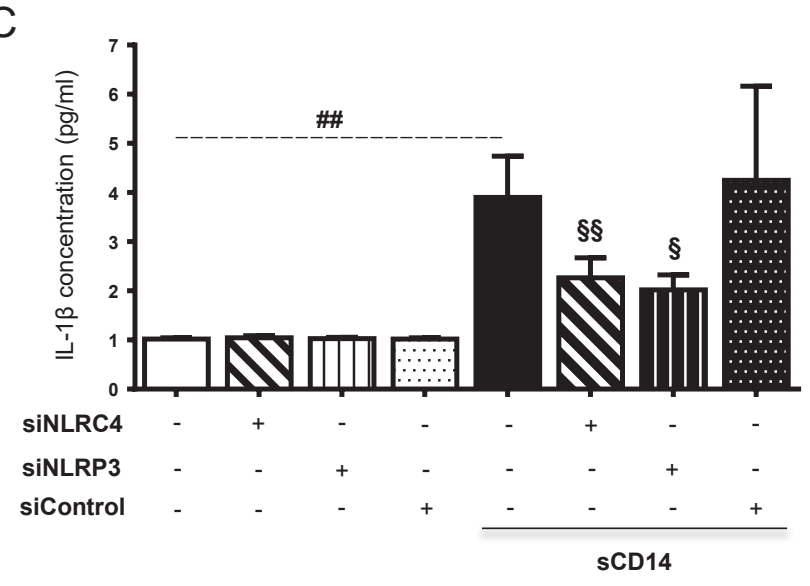


Fig 9

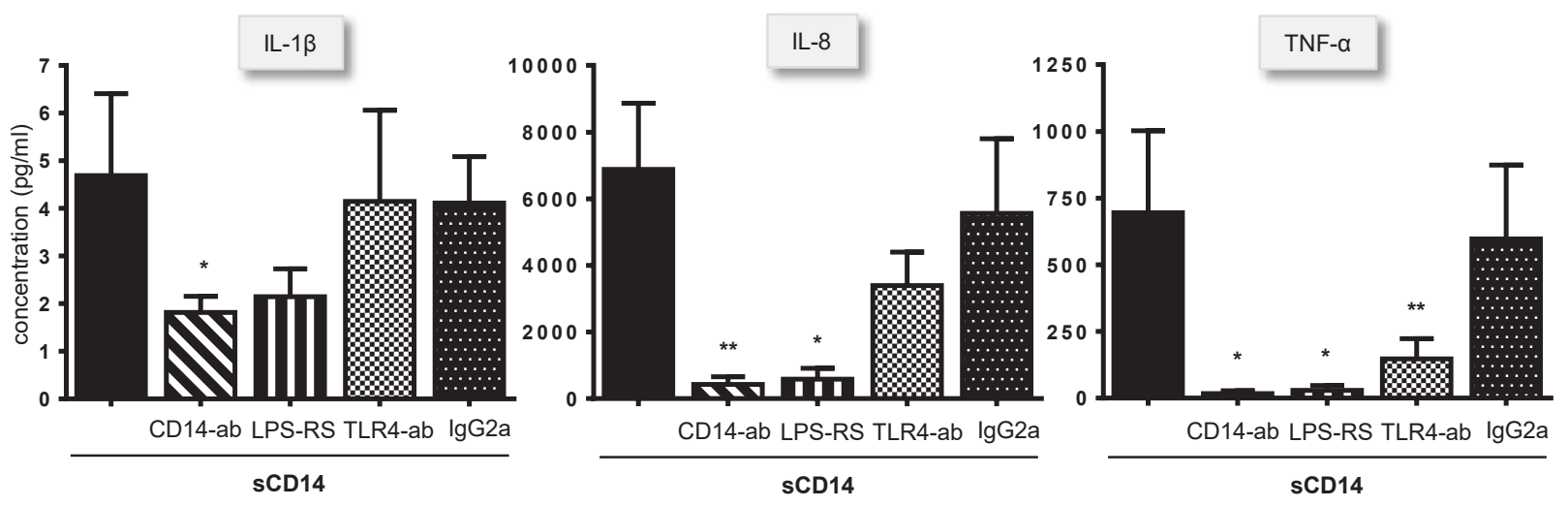


Table S1: Characteristics of CF patients

\begin{tabular}{|c|c|c|c|c|c|c|}
\hline Patient & Age & Sex & Genotype & Microbiology & BMI & FEV1 \% predicted \\
\hline 1 & 32 & $\mathrm{~F}$ & F508del / F508del & P.a / A.f / S.a & 15 & 45 \\
\hline 2 & 33 & M & F508del / F508del & P.a / A.f / S.a & 22,9 & 66 \\
\hline 3 & 34 & $\mathrm{~F}$ & F508del / W486X & P.a / S.a & 19,6 & 37 \\
\hline 4 & 22 & $\mathrm{~F}$ & F508del / F508del & P.a / A.f / S.a & 16,8 & 32 \\
\hline 5 & 39 & M & F508del / G551D & Af & 22,1 & 40 \\
\hline 6 & 32 & $\mathrm{M}$ & F508del / F508del & P.a/S.a & 20,1 & 82 \\
\hline 7 & 20 & $\mathrm{M}$ & F508del / F508del & P.a / A.f / S.a & 19,9 & 66 \\
\hline 8 & 20 & M & F508del / F508del & S.a & 23,2 & 98 \\
\hline 9 & 39 & $\mathrm{~F}$ & F508del / 2789+5G $\rightarrow A$ & P.a/S.a & 19,3 & 66 \\
\hline 10 & 22 & $\mathrm{M}$ & F508del / F508del & A.f / S.a & 19,5 & 78 \\
\hline 11 & 22 & $\mathrm{~F}$ & $1248+1 \mathrm{G} \rightarrow \mathrm{A}$ & S.a & 22,7 & 104 \\
\hline 12 & 20 & $\mathrm{~F}$ & F508del / I507del & P.a / A.f & 18,4 & 61 \\
\hline 13 & 30 & $\mathrm{~F}$ & F508del / 1248+1G $\rightarrow A$ & P.a/S.a & 18,3 & 33 \\
\hline 14 & 31 & $\mathrm{~F}$ & F508del / N1303K & P.a / A.f / S.a & 15,4 & 28 \\
\hline 15 & 22 & $\mathrm{~F}$ & F508del / F508del & P.a/A.f/S.a & 19,6 & 79 \\
\hline 16 & 34 & M & F508del / F508del & P.a / A.f / S.a & 20,5 & 51 \\
\hline 17 & 27 & $\mathrm{~F}$ & F508del / F508del & A.f / S.a & 20,5 & 97,2 \\
\hline 18 & 35 & $\mathrm{~F}$ & F508del / F508del & P.a/S.a & 19,1 & 30,2 \\
\hline 19 & 43 & M & F508del / G551D & P.a & 20,9 & 79,1 \\
\hline 20 & 28 & $\mathrm{~F}$ & $1248+1 \mathrm{G} \rightarrow \mathrm{A}$ & A.f / S.a & 20,7 & 90,5 \\
\hline 21 & 40 & M & F508del / F508del & P.a / A.f & 21,9 & 48,7 \\
\hline 22 & 18 & $\mathrm{~F}$ & F508del / F508del & None & 24,1 & 100,4 \\
\hline 23 & 37 & $\mathrm{~F}$ & R600S / CFTRdup4-10 & S.a & 18,6 & 95 \\
\hline 24 & 20 & $\mathrm{~F}$ & F508del / S945L & A.f / S.a & 21,3 & 68,4 \\
\hline 25 & 25 & $\mathrm{M}$ & F508del / F508del & A.f / S.a & 24,4 & 58,5 \\
\hline 26 & 24 & $\mathrm{~F}$ & F508del / F508del & P.a / A.f / S.a & 16,5 & 28,4 \\
\hline 27 & 19 & $\mathrm{M}$ & F508del / $2789+5 G \rightarrow A$ & S.a & 22,23 & 94,7 \\
\hline 28 & 40 & $\mathrm{~F}$ & F508del / S492F & P.a / S.a & 27,82 & 55,3 \\
\hline 29 & 53 & $\mathrm{~F}$ & F508del / 2789+5G $\rightarrow A$ & P.a / A.f & 17,61 & 36 \\
\hline 30 & 28 & $\mathrm{M}$ & F508del / F508del & A.f & 23,74 & 103 \\
\hline 31 & 53 & M & F508del / 2789+5G $\rightarrow A$ & S.a & 22,14 & 96,2 \\
\hline 32 & 20 & $\mathrm{M}$ & F508del / F508del & A.f / S.a & 22,3 & 62 \\
\hline 33 & 19 & $\mathrm{M}$ & F508del / F508del & P.a / A.f & 20,4 & 91 \\
\hline 34 & 26 & $\mathrm{M}$ & F508del / F508del & S.a & 20,2 & 58,7 \\
\hline 35 & 37 & M & F508del / F508del & S.a & 21,1 & 77,4 \\
\hline 36 & 23 & $\mathrm{~F}$ & F508del / F508del & S.a & 17,1 & 54,5 \\
\hline 37 & 49 & $\mathrm{~F}$ & F508del / 3272-26A $\rightarrow G$ & P.a / S.a & 22,8 & 62,2 \\
\hline 38 & 31 & $\mathrm{~F}$ & F508del / G91R & P.a/S.a & 24,3 & 61,5 \\
\hline 39 & 19 & $\mathrm{~F}$ & F508del / F508del & S.a & 18,8 & 96 \\
\hline 40 & 27 & M & F508del / F508del & S.a & 20,2 & 73,1 \\
\hline 41 & 26 & $\mathrm{~F}$ & F508del / F508del & P.a / A.f / S.a & 19,1 & 67 \\
\hline 42 & 33 & M & F508del / F508del & P.a & 22,2 & 64,4 \\
\hline 43 & 18 & $\mathrm{~F}$ & F508del / F508del & None & 25,8 & 102,1 \\
\hline 44 & 37 & $\mathrm{~F}$ & F508del / F508del & S.a & 19,1 & 77,5 \\
\hline 45 & 21 & $\mathrm{~F}$ & F508del / G551D & S.a & 22,5 & 103,7 \\
\hline 46 & 46 & $\mathrm{M}$ & F508del / 2789+5G $\rightarrow A$ & A.f / S.a & 22,2 & 96,6 \\
\hline 47 & 35 & $\mathrm{~F}$ & F508del / F508del & P.a/S.a & 19,3 & 35,2 \\
\hline 48 & 25 & M & F508del / F508del & A.f / S.a & 23,5 & 55,3 \\
\hline 49 & 39 & M & F508del / F508del & P.a & 21 & 49 \\
\hline 50 & 18 & $\mathrm{~F}$ & F508del / F508del & P.a / A.f / S.a & 19,1 & 62,3 \\
\hline 51 & 23 & M & F311L / N1303K & S.a & 18,5 & 93,8 \\
\hline 52 & 21 & $\mathrm{~F}$ & F508del / F508del & P.a/A.f/S.a & 18,4 & 86,7 \\
\hline 53 & 26 & $M$ & F508del / S1251N & P.a / S.a & 18,81 & 41,1 \\
\hline 54 & 23 & $\mathrm{~F}$ & F508del / F508del & P.a/S.a & 16,86 & 33,7 \\
\hline 55 & 38 & $\mathrm{~F}$ & F508del / F508del & None & 18,2 & 41 \\
\hline 56 & 30 & $\mathrm{M}$ & F508del / 1749insTA & P.a / A.f / S.a & 18,3 & 21,1 \\
\hline 57 & 32 & $\mathrm{~F}$ & F508del / 4382delA & P.a / A.f / S.a & 18 & 29,5 \\
\hline 58 & 23 & $\mathrm{~F}$ & F508del / 1677delTA & P.a / A.f & 18 & 49 \\
\hline 59 & 52 & $\mathrm{M}$ & F508del / 2789+5G $\rightarrow A$ & Af & 22,5 & 107,9 \\
\hline 60 & 38 & M & F508del / 1078delT & P.a / A.f / S.a & 21,7 & 63 \\
\hline
\end{tabular}

Abbreviations : A.f.: Aspergillus fumigatus; P.a.: Pseudomonas aeruginosa; S.a.: Staphylococcus aureus FEV1: Force Expiratory Volume in one second 
Table S2: List of primer sequences used for RT-qPCR analysis in this study

\begin{tabular}{|c|c|c|}
\hline Target genes & Primer & Sequence ( $5^{\prime}$ to $\left.3^{\prime}\right)$ \\
\hline $18 S$ & Hs_RRN18S_1_SG & QT00199367 \\
\hline \multirow[t]{2}{*}{$18 S$} & Forward & CGCCGCTAGAGGTGAAATTC \\
\hline & Reverse & TTGGCAAATGCTTTCGCTC \\
\hline CD14 & Hs_CD14_1_SG & QT00208817 \\
\hline IL-1 $\beta$ & Hs_IL1B_1_SG & QT00021385 \\
\hline IL-8 & $\mathrm{Hs}$ CXXCL8_- 1 _SG & QT00000322 \\
\hline \multirow[t]{2}{*}{ TNF $\alpha$} & Forward & ААССТССТСТСТGССАТС \\
\hline & Reverse & ATGTTCGTCCTCСTCACA \\
\hline \multirow[t]{2}{*}{ MMP-9 } & Forward & TCTTCCCTGGAGACCTGAGA \\
\hline & Reverse & АTTTCGACTCTCCACGCATC \\
\hline \multirow[t]{2}{*}{ MMP-12 } & Forward & ACACATTTCGCСTCTCTGCT \\
\hline & Reverse & ATTGTCAGGATTTGGCAAGC \\
\hline \multirow[t]{2}{*}{ Cathepsin B } & Forward & AGAATGGCACACCCTACTGG \\
\hline & Reverse & GCCACCACTTCTGATTCGAT \\
\hline \multirow[t]{2}{*}{ Cathepsin D } & Forward & GTACATGATCCСCTGTGAGAAGGT \\
\hline & Reverse & GGGACAGCTTGTAGCCTTTGC \\
\hline \multirow[t]{2}{*}{ Cathepsin F } & Forward & GCCTGTCCGTCTTTGTCAAT \\
\hline & Reverse & TGGCTTGCTTCATCTTGTTG \\
\hline \multirow[t]{2}{*}{ Cathepsin K } & Forward & CCGCAGTAATGACACCCTTT \\
\hline & Reverse & GCACCCACAGAGCTAAAAGC \\
\hline \multirow[t]{2}{*}{ Cathepsin S } & Forward & TGGGAGACATGACCAGTGAA \\
\hline & Reverse & AGCAAGCACCACAAGAACCT \\
\hline \multirow[t]{2}{*}{ Adam 9} & Forward & TGCAAATGTCTTCAGGGAAC \\
\hline & Reverse & TGCATTAACCTCACCGATGAC \\
\hline \multirow[t]{2}{*}{ Adam 10} & Forward & СATTGCTGAATGGATTGTGG \\
\hline & Reverse & GAGCCTGGAAGTGGTTTACG \\
\hline \multirow[t]{2}{*}{ Adam 12} & Forward & AACCTCGCTGCAAAGAATGTG \\
\hline & Reverse & СTCTGAAACTCTCGGTTGTCTG \\
\hline \multirow[t]{2}{*}{ Adam 17} & Forward & ACCTGAAGAGCTTGTTCATCGAG \\
\hline & Reverse & CCATGAAGTGTTCCGATAGATGTC \\
\hline \multirow[t]{2}{*}{ PLC $\gamma$} & Forward & AACCAGAAGTCCTTTGTCTTCATC \\
\hline & Reverse & CTGGTTCTTCTCCСAGTACTTCAT \\
\hline
\end{tabular}



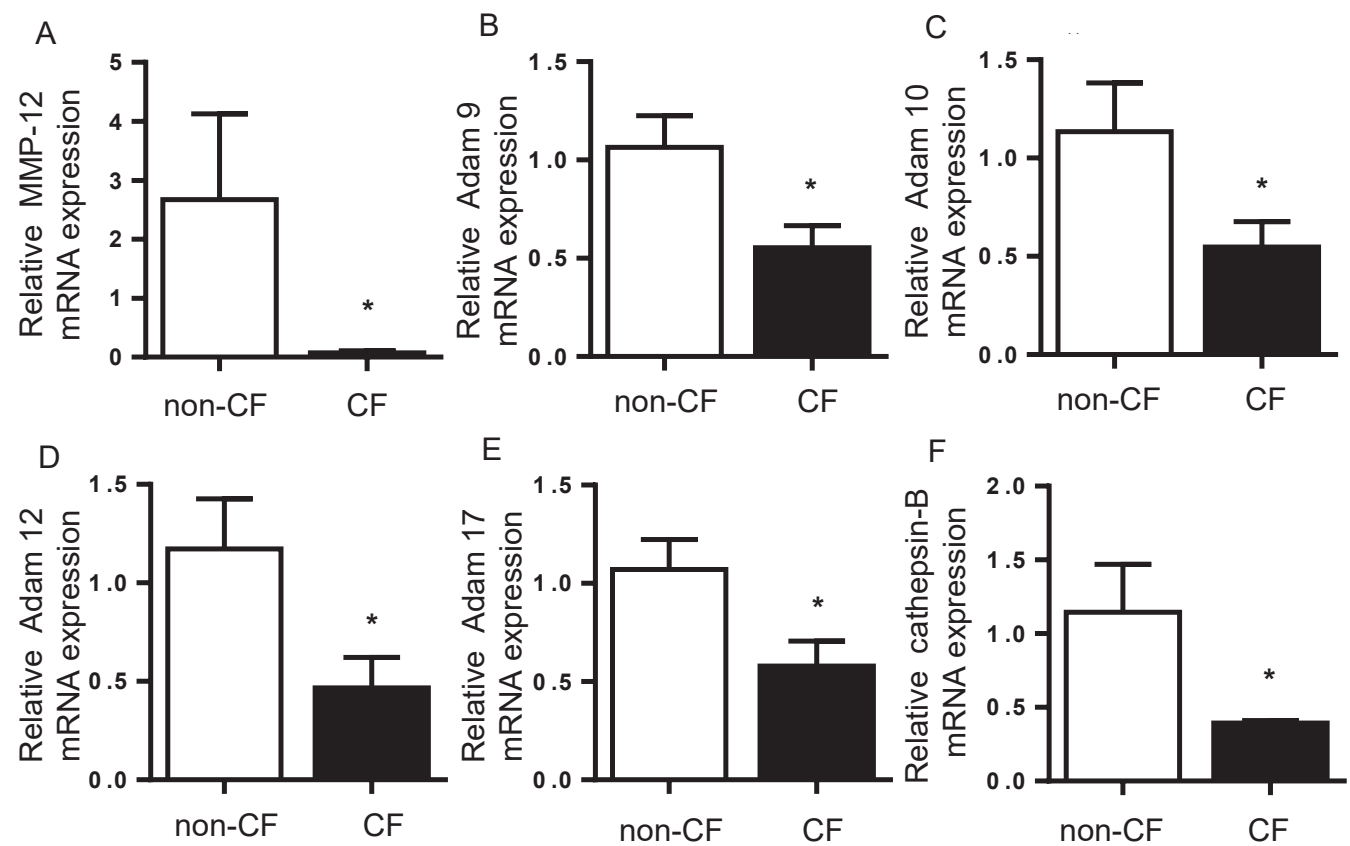

E
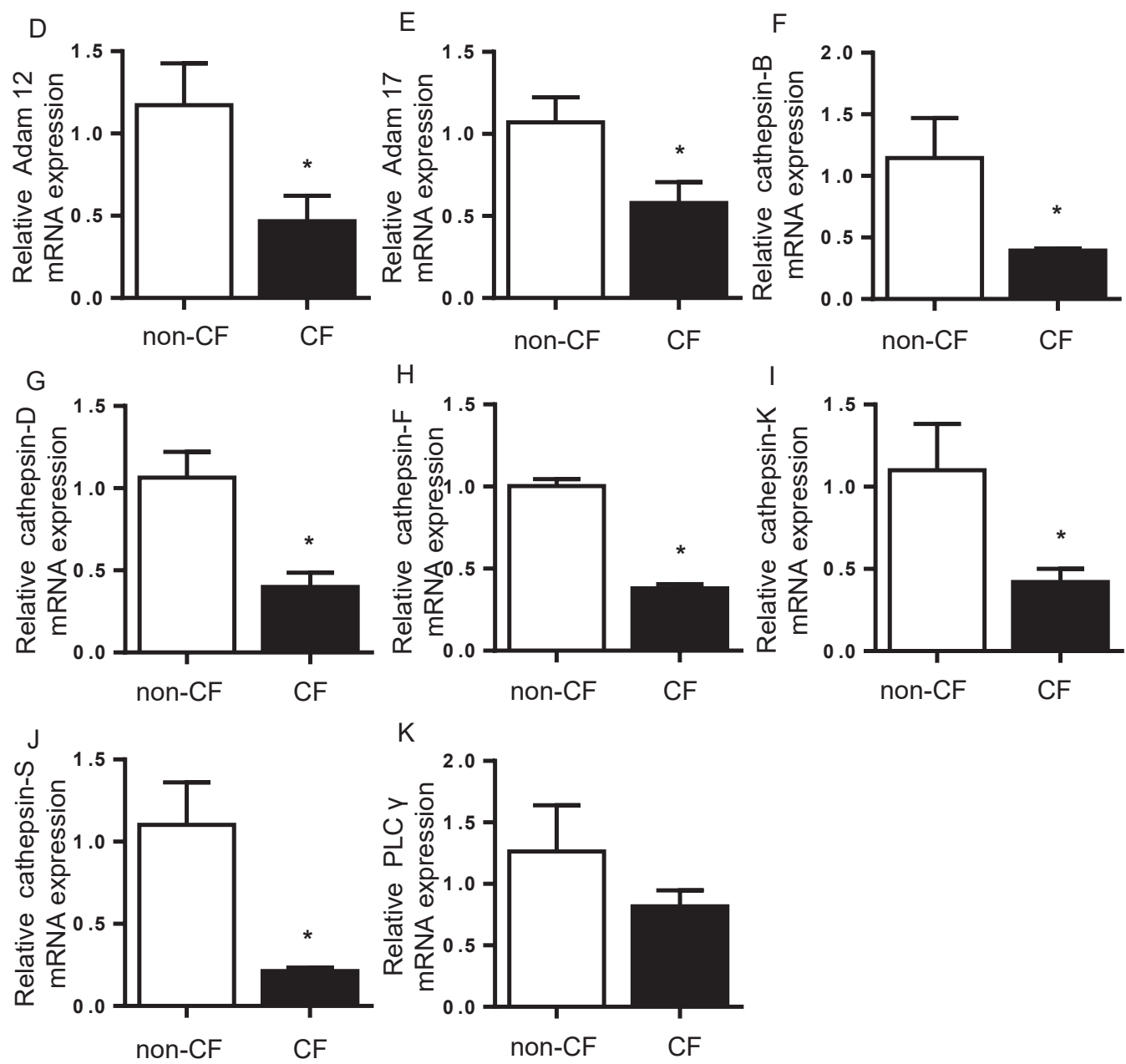

K

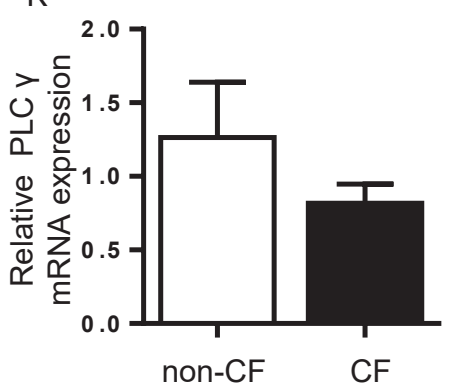

FIGURE S1. Proteases and phospholipase $\mathrm{C}-\gamma$ gene expressions in non-CF and $\mathbf{C F}$ macrophages. $(A)$ MMP-12 ( $n=4$, patients 6, 13, 15-16; supplemental Table 1), (B to E) Adam 9, Adam 10, Adam 12 ( $\mathrm{n}=6$, patients 17-18, 20-22, 24; supplemental Table 1) and Adam $17(\mathrm{n}=6$, patients 17, 21-22, 24, 26, 41; supplemental Table 1), ( $F$ to $J$ ) cathepsin-B, cathepsin-D, cathepsin-F, cathepsin-K and cathepsin-S ( $n=3$ 6, patients 15-16, 32; supplemental Table 1) and (K) phospholipase C- $\gamma$ (PLC $\gamma, n=5-6$, patients 17, 18, 20, 22, 24; supplemental Table 1). Gene (mRNA) expression was quantified in CF and non-CF macrophages by RT-qPCR. The data are shown as the mean \pm SEM. Mann-Whitney test: ${ }^{*} \mathrm{p}<0.05$ vs. non-CF macrophages. 

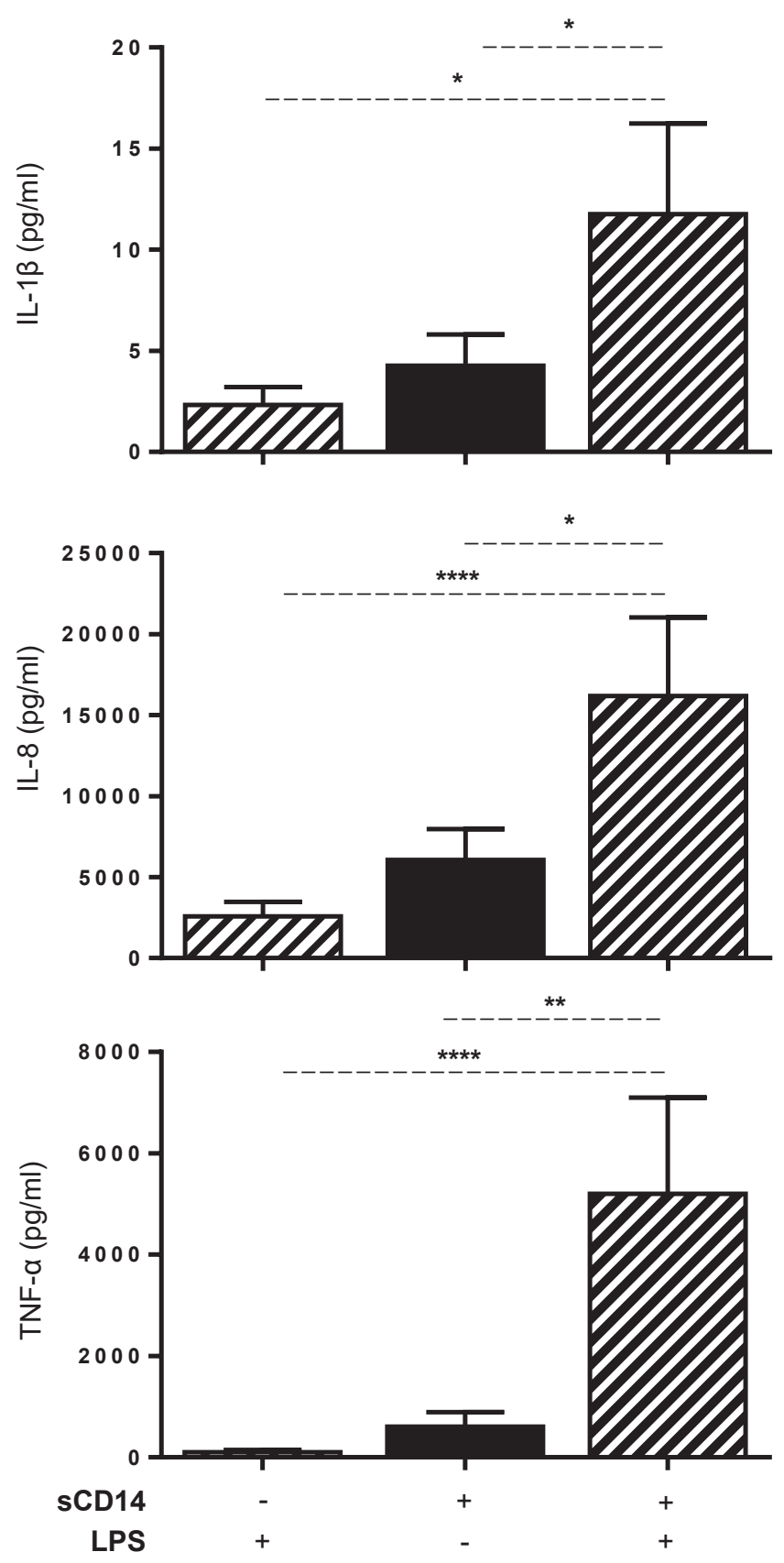

FIGURE S2. sCD14 potentiates LPS-induced inflammatory cytokines/chemokines production in non-CF macrophages. IL- $1 \beta$, IL- 8 and TNF- $\alpha$ levels were measured using an ELISA assay in non-CF macrophages incubated with LPS (from P. aeruginosa, $100 \mathrm{ng} / \mathrm{ml}$ ) in the absence and presence of sCD14 $(500 \mathrm{ng} / \mathrm{ml})(n=8)$. Ratio Student's t-test: ${ }^{*} \mathrm{p}<0.05 ; * * \mathrm{p}<0.01$ and $* * * * \mathrm{p}<0.0001$ vs LPS-treated macrophages. 